\title{
Polarity directed optimization of phytochemical and in vitro biological potential of an indigenous folklore: Quercus dilatata Lindl. ex Royle
}

\author{
Madiha Ahmed', Humaira Fatima', Muhammad Qasim², Bilquees Gul ${ }^{2}$ and Ihsan-ul-Haq ${ }^{1 *}$
}

\begin{abstract}
Background: Plants have served either as a natural templates for the development of new chemicals or a phytomedicine since antiquity. Therefore, the present study was aimed to appraise the polarity directed antioxidant, cytotoxic, protein kinase inhibitory, antileishmanial and glucose modulatory attributes of a Himalayan medicinal plant- Quercus dilatata.

Methods: Total phenolic and flavonoid contents were determined colorimetrically and various polyphenols were identified by RP-HPLC analysis. Brine shrimp lethality, SRB and MTT assays were employed to test cytotoxicity against Artemia salina and human cancer cell lines respectively. Antileishmanial activity was determined using standard MTT protocol. Glucose modulation was assessed by a-amylase inhibition assay while disc diffusion assay was used to establish protein kinase inhibitory and antifungal spectrum.

Results: Among 14 extracts of aerial parts, distilled water-acetone extract demonstrated maximum extract recovery $(10.52 \% \mathrm{~W} / \mathrm{W})$, phenolic content $(21.37 \pm 0.21 \mu \mathrm{g} \mathrm{GAE} / \mathrm{mg}$ dry weight $(\mathrm{DW}))$, total antioxidant capacity $(4.81 \pm 0.98 \mu \mathrm{g} \mathrm{AAE} / \mathrm{mg} \mathrm{DW})$ and reducing power potential $(20.03 \pm 2.4 \mu \mathrm{g} / \mathrm{mg} \mathrm{DW})$. On the other hand, Distilled water extract proficiently extracted flavonoid content (4.78 $\pm 0.51 \mu \mathrm{g} \mathrm{QE} / \mathrm{mg} \mathrm{DW})$. RP-HPLC analysis revealed the presence of significant amounts of phenolic metabolites $(0.049$ to $15.336 \mu \mathrm{g} / \mathrm{mg}$ extract) including, pyrocatechol, gallic acid, catechin, chlorogenic acid, p-coumaric acid, ferulic acid and quercetin. Highest free radical scavenging capacity was found in Methanol-Ethyl acetate extract $\left(I C_{50} 8.1 \pm 0.5 \mu \mathrm{g} / \mathrm{ml}\right)$. In the brine shrimp toxicity assay, most of the tested extracts (57\%) showed high cytotoxicity. Among these, Chloroform-Methanol extract had highest cytotoxicity against THP-1 cell line $\left(\mathrm{IC}_{50} 3.88 \pm 0.53 \mu \mathrm{g} / \mathrm{ml}\right)$. About $50 \%$ of the extracts were found to be moderately antiproliferative against Hep G2 cell line. Methanol extract exhibited considerable protein kinase inhibitory activity against Streptomyces $85 \mathrm{E}$ strain $(28 \pm 0.35 \mathrm{~mm}$ bald phenotype at $100 \mu \mathrm{g} / \mathrm{disc}$; MIC = $12.5 \mu \mathrm{g} /$ disc) while, Chloroform extract displayed maximum antidiabetic activity (a-amylase inhibition of $21.61 \pm 1.53 \%$ at $200 \mu \mathrm{g} / \mathrm{ml}$ concentration). The highest antileishmanial potential was found in Ethyl acetate-Acetone extract $(12.91 \pm 0.02 \%$ at $100 \mu \mathrm{g} / \mathrm{ml}$ concentration), while, $Q$. dilatata extracts also showed a moderate antifungal activity.
\end{abstract}

Conclusion: This study proposes that multiple-solvent system is a crucial variable to elucidate pharmacological potential of $Q$. dilatata and the results of the present findings prospects its potential as a resource for the discovery of novel anticancer, antidiabetic, antileishmanial and antioxidant agents.

Keywords: Antileishmanial, Antioxidant, Cytotoxicity, Hep G2, Protein kinase inhibition, THP-1 leukemia cell line

\footnotetext{
*Correspondence: ihsn99@yahoo.com; ihaq@qau.edu.pk

'Department of Pharmacy, Faculty of Biological Sciences, Quaid-i-Azam

University, Islamabad 45320, Pakistan

Full list of author information is available at the end of the article
} 


\section{Background}

Bioactive phytoconstituents include an array of compounds (e.g., tannins, lignans, coumarins, quinones, stilbenes, xanthones, phenolic acids, flavones, flavonols, catechins, anthocyanins, and proanthocyanins) that could delay or deter the inception of diseases such as cancer and diabetes [1]. They have also contributed to the pharmacopeia of the world for the provision of new and effective agents against infectious diseases such as leishmaniasis [2]. Mounting the credibility of traditional medicinal plants requires consolidation of scientific data to fill the research based evidence gaps. Therefore, the present study is designed to appraise the antioxidant, cytotoxic, kinases inhibitory, antileishmanial and antidiabetic properties of a folklore medicinal plant; Quercus dilatata.

Quercus dilatata Lindl. ex Royle (Synonym; Quercus floribunda Lindl. Camus), known commonly as Holly Oak and locally as Bunj or Barungi, belongs to family Fagaceae. The genus Quercus encompassing around 400 species is distributed in America, temperate Europe, Asia and sub-tropical Africa. In Pakistan this evergreen tree is abundant in the Himaliyan mountains specially in Dir, Chitral, Swat, Hazara, Tirah, Kurram Agency, Murree hills and Azad Kashmir [3]. Powdered form of its fruits are utilized for the eradication of gonorrhoea and urinary tract infections in district Swat [4]. Leaves and seeds are utilized against sore mouth and throat in Lawat district [5]. Seeds are also believed to be astringent, diuretic and are employed in diarrhoea, indigestion and asthma in Poonch Valley [6].

Extraction efficiency and bioactivity of herbal extracts can be optimized by varying extraction solvent polarity [7]. In this study, multiple mono and binary solvent systems of escalating polarities were applied to find out most proficient system for the extraction of antioxidant, cytotoxic, protein kinase inhibitory, antidiabetic and/or antimicrobial potential of $Q$. dilatata. To the best of our knowledge, protein kinase inhibitory, antileishmanial, antidiabetic and cytotoxic (against THP-1 and Hep G2 human cancer cell lines) activities of $Q$. dilatata extracts are being reported for the first time here.

\section{Methods}

\section{Solvents and reagents}

Solvents (n-Hexane, chloroform, acetone, ethyl acetate, methanol, ethanol and DMSO), gallic acid, quercetin, aluminium chloride $\left(\mathrm{AlCl}_{3}\right)$, potassium acetate, 2,2-diphenyl-1-picrylhydrazyl (DPPH), ascorbic acid, sulfuric acid $\left(\mathrm{H}_{2} \mathrm{SO}_{4}\right)$, ammonium molybdate, monosodium dihydrogen phosphate $\left(\mathrm{NaH}_{2} \mathrm{PO}_{4}\right)$, trichloroacetic acid (TCA), potassium ferricyanide, ferric chloride $\left(\mathrm{FeCl}_{3}\right)$, standard antibiotics (cefixime, ciprofloxacin), standard antifungal (clotrimazole), trypton soy broth (TSB), $\alpha$-amylase enzyme (from Bacillus subtilis), acarbose, phosphate buffer (PB),
Folin-Ciocalteu reagent, RPMI-1640 medium, Medium 119, DMEM and sea salt were purchased from Sigma (Sigma-Aldrich Germany). Sabouraud dextrose agar (SDA) was purchased from Oxoid England; Tween-20 from Merck-Schuchardt, USA. Medium ISP4 was prepared in lab while doxorubicin was purchased from Merck (Darmstadt, Germany).

\section{Collection and extraction}

Aerial parts of $Q$. dilatata were collected during September 2013 from Murree hills, Pakistan and identified by Prof. Dr. Rizwana Aleem Qureshi, Department of Plant Sciences, Faculty of Biological Sciences, Quaid-i-Azam University Islamabad, Pakistan. Voucher specimen (PHM-490) was archived in the herbarium of medicinal plants, Department of Pharmacy, Quaid-i-Azam University, Islamabad. The plant was thoroughly washed under running water and shade dried with active ventilation at ambient temperature for three weeks. The dried plant material was pulverised to fine powder and stored in air-tight containers till further use. The powdered plant (40 g) was subjected to sonication aided maceration for $24 \mathrm{~h}$ at room temperature using analytical grade solvents $(400 \mathrm{ml})$ in $1000 \mathrm{ml}$ Erlenmeyer flask. The extracts were concentrated by vacuum evaporation in rotary evaporator (Buchi, Switzerland) and dried in vacuum oven (Yamato, Japan) at $45{ }^{\circ} \mathrm{C}$ to obtain final crude extract. The experiment was run in triplicate. The solvents included n-Hexane (NH), Chloroform (C), Acetone (A), Ethyl acetate + Acetone (EtA), Ethyl acetate (Et), Chloroform + Ethanol $(\mathrm{CE})$, Chloroform + Methanol (CM), Ethanol + Ethyl acetate (EEt), Methanol + Ethyl acetate (MEt), Ethanol (E), Distilled water + Acetone (DA), Methanol (M), Distilled water + Methanol (DM) and Distilled water (D). A ratio of 1:1 was used for the preparation of binary solvent systems. The extracts were stored at $-30{ }^{\circ} \mathrm{C}$ for further testing.

\section{Extract recovery}

The dried extracts were weighed to calculate \% recovery of crude extracts by the following formula.

$$
\text { Extract recovery }(\% \mathrm{w} / \mathrm{w})=(\mathrm{A} / 40) \times 100
$$

Where; $\mathrm{A}=$ weight of crude extract obtained after drying.

\section{Phytochemical analysis}

Stock solution of each crude extract in DMSO $(4 \mathrm{mg} / \mathrm{ml})$ was prepared for phytochemical analysis.

\section{Determination of total phenolic content (TPC)}

Folin-Ciocalteu (FC) reagent method was used to estimate total phenolic content $[8,9]$. An aliquot of $20 \mu \mathrm{l}$ from stock solution and $90 \mu \mathrm{l}$ of FC reagent in 96 well plate was incubated for $5 \mathrm{~min}$ at room temperature followed by the 
addition of $90 \mu \mathrm{l}$ of sodium carbonate solution. Absorbance of the assay plate was recorded at $630 \mathrm{~nm}$ using microplate reader (Biotech USA, microplate reader Elx 800). A calibration curve $(y=0.0136 x+0.0845$, $\left.\mathrm{R}^{2}=0.9861\right)$ was obtained under the same operating conditions using gallic acid $(6.25-50 \mu \mathrm{g} / \mathrm{ml})$ as a positive standard. The assay was performed in triplicate and the results are expressed as microgram gallic acid equivalent per milligram dry weight ( $\mu \mathrm{g} \mathrm{GAE} / \mathrm{mg} \mathrm{DW})$.

\section{Determination of total flavonoid content (TFC)}

Total flavonoid content was estimated by aluminium chloride colorimetric method with minor modifications $[10,11]$. Briefly $20 \mu \mathrm{l}$ from each test sample stock solution, $10 \mu \mathrm{l}$ of aluminium chloride $\left(10 \% w / v\right.$ in $\left.\mathrm{H}_{2} \mathrm{O}\right)$, $10 \mu \mathrm{l}$ of $1.0 \mathrm{M}$ potassium acetate and $160 \mu \mathrm{l}$ of distilled water were added in 96 well plate which was incubated at room temperature for $30 \mathrm{~min}$. The absorbance of the plate was measured at $415 \mathrm{~nm}$ using microplate reader. A calibration curve $\left(y=0.0268 x+0.00764, R^{2}=0.9851\right)$ of quercetin was drawn at final concentrations of $2.5,5$, $10,20,40 \mu \mathrm{g} / \mathrm{ml}$ and the resultant flavonoid content is expressed in microgram equivalents of quercetin per milligram dry weight ( $\mu \mathrm{g} \mathrm{QE} / \mathrm{mg} \mathrm{DW})$.

\section{RP-HPLC quantitative analysis}

High performance liquid chromatography was performed according to previously described procedure $[12,13]$. Dried extracts $(0.5 \mathrm{~g})$ were dissolved in methanol (62.5\%) and $6 \mathrm{M} \mathrm{HCl}$ solution. After purging nitrogen for few sec, samples were refluxed for $2 \mathrm{~h}$. Filtered extracts were adjusted to $100 \mathrm{ml}$ (with methanol) and refiltered through $0.45 \mu \mathrm{m}$ membrane filter (Millex-HV) before injecting into HPLC. The HPLC system (Shimadzu LC-20AT) was equipped with auto-sampler (SIL-20A), column oven (CTO-20A), and diode array detector (SPDM20A). Analytical column- Nucleosil C18, $5 \mu \mathrm{m} 100 \mathrm{~A}^{\circ}$ $(250 \times 4.60 \mathrm{~mm}$, Phenomenex) coupled with a guard column (KJO-4282, Phenomenex) was used. Mobile phase was composed of $1 \%$ acetic acid solution and $70 \%$ methanol. Gradient program by Araruna et al. [14] was used with a flow rate of $0.8 \mathrm{ml} / \mathrm{min}$. Phenolic compounds were identified by comparing retention time and UV-vis spectra of chromatographic peaks with that of authentic reference standards at $280 \mathrm{~nm}$.

\section{Biological evaluation \\ Antioxidant assays}

Free radical scavenging activity (FRSA) The FRSA of the crude extracts was evaluated by monitoring their capability to quench the stable 2, 2-diphenyl-1-picrylhydrazyl $(\mathrm{DPPH})$ free radical $[8,15]$. Briefly, $20 \mu \mathrm{l}$ of four different dilutions of each test sample to have final concentrations of 200, 66.66, 22.22 and $7.41 \mu \mathrm{g} / \mathrm{ml}$, were mixed with $180 \mu \mathrm{l}$ of DPPH solution $(9.2 \mathrm{mg} / 100 \mathrm{ml}$ methanol) in 96 well plate. After incubating the plate for $30 \mathrm{~min}$ at $37{ }^{\circ} \mathrm{C}$, absorbance was recorded at $517 \mathrm{~nm}$. Percent free radical scavenging activity (\%FRSA) was calculated by using the formula:

$$
\% \mathrm{FRSA}=\left(1-\mathrm{Ab}_{\mathrm{s}} / \mathrm{Ab}_{\mathrm{c}}\right) \times 100
$$

Where $A b_{s}$ is the absorbance of test sample, whereas $A b_{c}$ is the absorbance of negative control containing the DMSO instead of sample. Ascorbic acid was used as positive control and the assay was performed in triplicate. Afterwards $\mathrm{IC}_{50}$ of samples with significant radical scavenging efficiency $(>50 \%)$ was also calculated.

Total antioxidant capacity (TAC) Phosphomolybdenum based colorimetric assay was employed to determine total antioxidant capacity and is expressed as the number of microgram equivalents of ascorbic acid per milligram of dry plant weight ( $\mu \mathrm{g} \mathrm{AAE} / \mathrm{mg} \mathrm{DW}$ ) $[10,16]$. An aliquot of $0.1 \mathrm{ml}$ of each test extract (4 $\mathrm{mg} / \mathrm{ml}$ DMSO) and positive control (ascorbic acid, $4 \mathrm{mg} / \mathrm{ml}$ DMSO) was mixed with $0.9 \mathrm{ml}$ of reagent (0.6 $\mathrm{M}$ sulphuric acid, $28 \mathrm{mM}$ sodium phosphate and $4 \mathrm{mM}$ ammonium molybdate solution in $\mathrm{H}_{2} \mathrm{O}$ ). Blank contained $0.9 \mathrm{ml}$ of reagent solution and $0.1 \mathrm{ml}$ of DMSO without extract. All tubes were kept in water bath for $90 \mathrm{~min}$ at $95{ }^{\circ} \mathrm{C}$ and then cooled to room temperature from which $200 \mu \mathrm{l}$ of each sample was transferred to 96 well plate and the absorbance of each sample was measured at $630 \mathrm{~nm}$ using microplate reader (Biotech USA, microplate reader Elx 800). A calibration curve $(\mathrm{y}=0.0212 x+0.0926$, $\left.\mathrm{R}^{2}=0.9913\right)$ of ascorbic acid was drawn at final concentrations of $100,50,25,12.5,6.25,3.12 \mu \mathrm{g} / \mathrm{ml}$ and the experiment was performed in triplicate.

Total reducing power (TRP) Standard potassium ferricyanide colorimetric assay was performed to estimate the reducing power of different solvent extracts [10,17]. An aliquot of $200 \mu \mathrm{l}$ of test extracts $(4 \mathrm{mg} / \mathrm{ml} \mathrm{DMSO})$ was mixed with $400 \mu \mathrm{l}$ of each phosphate buffer $(0.2 \mathrm{~mol} / \mathrm{l}, \mathrm{pH}$ 6.6) and potassium ferricyanide $(1 \% \mathrm{w} / \mathrm{v}$ in $\mathrm{H}_{2} \mathrm{O}$ ). The mixture was incubated for $20 \mathrm{~min}$ at $50{ }^{\circ} \mathrm{C}$ followed by addition of $400 \mu \mathrm{l}$ of trichloroacetic acid $\left(10 \% w / v\right.$ in $\left.\mathrm{H}_{2} \mathrm{O}\right)$ and centrifuged at $3000 \mathrm{rpm}$ at room temperature for $10 \mathrm{~min}$. The upper layer of solution $(500 \mu \mathrm{l})$ was mixed with distilled water $(500 \mu \mathrm{l})$ and $100 \mu \mathrm{l}$ of $\mathrm{FeCl}_{3}\left(0.1 \% w / v\right.$ in $\left.\mathrm{H}_{2} \mathrm{O}\right)$. From this mixture, $200 \mu \mathrm{l}$ was transferred to 96 well plate and the absorbance of the reaction mixture was measured at $630 \mathrm{~nm}$. Blank was prepared by adding $200 \mu \mathrm{l}$ of DMSO to the aforesaid reaction mixture instead of extract. A 
calibration curve $\left(y=0.038 x+0.7484, R^{2}=0.9967\right)$ of ascorbic acid was obtained at final concentrations of $100,50,25,12.5,6.25,3.12 \mu \mathrm{g} / \mathrm{ml}$ and the resultant reducing power of each sample is expressed as $\mu \mathrm{g} \mathrm{AAE} / \mathrm{mg}$ DW. The assay was performed in triplicate.

\section{Cytotoxicity assays}

\section{Brine shrimp lethality assay}

A $24 \mathrm{~h}$ lethality test was performed in a 96 well plate against brine shrimp (Artemia salina) larvae as described previously [8]. Eggs of A. salina (Ocean star, USA) were incubated for $24-48 \mathrm{~h}$ hatching period under light and warmth $\left(30-32{ }^{\circ} \mathrm{C}\right)$ in simulated sea water (38 g/l supplemented with $6 \mathrm{mg} / \mathrm{l}$ dried yeast) in a specially designed two-compartment plastic tray. The mature phototropic nauplii (10) were then harvested with the help of Pasteur pipette and transferred to each well of plate. Corresponding volume of each extract containing $\leq 1 \%$ DMSO in sea water at final concentrations of 200, 100, 50 and $25 \mu \mathrm{g} / \mathrm{ml}$ was transferred to the wells containing sea water and shrimp larvae. The final volume in each well was kept $300 \mu \mathrm{l}$. Positive and negative control wells included serial concentrations of doxorubicin and 1\% DMSO in sea water respectively. After $24 \mathrm{~h}$ incubation, live shrimps were counted and the percentage of deaths was determined. Median lethal concentration $\left(\mathrm{LC}_{50}\right)$ was calculated using table curve $2 \mathrm{D}$ v5.01 software. The experiment was run in triplicate.

\section{Cytotoxicity against THP-1 human leukemia cell line}

The in vitro cytotoxicity evaluation of extracts against human leukemia (THP-1) cell line (ATCC \# TIB-202) was performed using standard protocol [18]. Concisely, leukemia cells were grown in complete growth medium [RPMI-1640 buffered with $2.2 \mathrm{~g} / \mathrm{l} \mathrm{NaHCO}_{3}$ and supplemented with $10 \% \mathrm{v} / \mathrm{v}$ heat inactivated foetal bovine serum (HIFBS); $\mathrm{pH}$ 7.4] in a humidified carbon dioxide incubator $\left(37^{\circ} \mathrm{C}, 5 \% \mathrm{CO}_{2}\right) .10 \mu \mathrm{l}$ of test sample containing 1\% DMSO in PBS was added in wells of microtitre plate to have a final concentration of $20 \mu \mathrm{g} / \mathrm{ml}$. Subsequently, an aliquot of $190 \mu \mathrm{l}$ of THP-1 cells (seeding density of $1 \times 10^{4}$ cells per ml) was transferred to each well. The culture was incubated at $37{ }^{\circ} \mathrm{C}$ for $72 \mathrm{~h}$ in humidified $\mathrm{CO}_{2}$ (5\%) incubator (Panasonic, Japan MCO-18 AC-PE). Serial concentrations of fluorouracil and vincristine were employed as positive controls whereas 1\% DMSO in PBS served as negative control. Afterwards, $20 \mu \mathrm{l}$ of pre-filter sterilized MTT solution ( $4 \mathrm{mg} / \mathrm{ml}$ in distilled $\mathrm{H}_{2} \mathrm{O}$ ) was added and plates were again incubated at $37{ }^{\circ} \mathrm{C}$ for $4 \mathrm{~h}$ in humidified $\mathrm{CO}_{2}(5 \%)$ incubator. After incubation supernatant was removed carefully by multi-channel pipette without disturbing coloured formazan sediments, which were equivalent to amount of live cells. To dissolve the formazan sediments
$100 \mu \mathrm{l}$ of DMSO was added in each well, the plate was kept aside for $1 \mathrm{~h}$ to ensure full dissolution and the absorbance was measured at $540 \mathrm{~nm}$ using microplate reader. Samples showing more than $50 \%$ cell mortality at $20 \mu \mathrm{g} / \mathrm{ml}$ were further analysed at lower concentrations i.e. 10, 5, 2.5 and $1.25 \mu \mathrm{g} / \mathrm{ml}$ and the assay was performed in triplicate. $\mathrm{IC}_{50}$ was calculated by using table curve $2 \mathrm{D}$ v5.01 software.

\section{Cytotoxicity against Hep G2 cell line}

The cytotoxic potential of extracts towards Hep G2 cancer cell line (RBRC-RCB1648) was determined by using SRB colorimetric assay as described previously [19]. Briefly, Hep G2 cells were grown in Dulbecco's Modified Eagle Medium (DMEM) supplemented with $10 \% \quad v / \mathrm{v}$ FBS, $100 \mathrm{IU} / \mathrm{ml}$ penicillin $\mathrm{G}$ sodium, $100 \mu \mathrm{g} / \mathrm{ml}$ streptomycin sulphate and $0.25 \mu \mathrm{g} / \mathrm{ml}$ amphotericin $B$. The plate was then incubated in humidified atmosphere at $37{ }^{\circ} \mathrm{C}$ and $5 \%$ $\mathrm{CO}_{2}$ for $72 \mathrm{~h}$ to obtain a confluence of approximately 60 $70 \%$. Old medium was replaced with fresh medium and the cells were incubated for another $24 \mathrm{~h}$ after which they were trypsonised and diluted to get an assay density of $1 \times 10^{5}$ cells $/ \mathrm{ml}$. An aliquot of $180 \mu \mathrm{l}$ from aforementioned culture was then transferred to each well of 96 well plate having $20 \mu \mathrm{l}$ of test samples (containing 1\% DMSO in PBS) to have final concentration of $20 \mu \mathrm{g} / \mathrm{ml}$. Doxorubicin $(20-0.08 \mu \mathrm{g} / \mathrm{ml})$ and $1 \% \nu / v$ DMSO in PBS instead of test sample were employed as positive and negative controls respectively. The culture plate was then incubated at $37{ }^{\circ} \mathrm{C}$ for $72 \mathrm{~h}$ in $\mathrm{CO}_{2}$ incubator. The incubation was stopped with the addition of $50 \mu$ of cold $20 \% \mathrm{w} / v$ TCA for $1 \mathrm{~h}$ at $4{ }^{\circ} \mathrm{C}$ for cell fixation. The fixed cells were washed 4 times with tap water, air dried and stained with $50 \mu \mathrm{l}$ of $0.057 \% w / v$ SRB in $1 \% w / v$ acetic acid for $30 \mathrm{~min}$ at room temperature. Wells were then washed 4 times with $1 \% v / \mathrm{v}$ acetic acid and the plates were dried overnight. Bound dye was solubilized in $200 \mu \mathrm{l} 10 \mathrm{mM}$ Tris base, $\mathrm{pH} \mathrm{10,} \mathrm{for} 1 \mathrm{~h}$. Optical density was measured on a micro-plate reader (Biotech USA, microplate reader Elx $800)$ at $515 \mathrm{~nm}$ and percent survival was determined. In each case, a zero-day control was performed by adding an equivalent number of cells to sixteen wells, incubating at $37^{\circ} \mathrm{C}$ for $1 \mathrm{~h}$ and processing as described above. Percent of cell growth inhibition was calculated using the formula:

$$
\begin{array}{r}
\text { \% Inhibition }=100-\left[\left(\mathrm{OD}_{\text {cells }+ \text { samples }}-\mathrm{OD}_{\text {day } 0}\right)\right. \\
\\
\left./\left(\mathrm{OD}_{\text {cells }+1 \% \mathrm{DMSO}}-\mathrm{OD}_{\text {day } 0}\right) \times 100\right]
\end{array}
$$

\section{Cytotoxicity against isolated lymphocytes}

Lymphocytes were isolated using formerly described procedure with slight modifications [20]. Informed consent was taken from volunteers and protocol was followed 
according to international ethical guidelines after approval from the ethical committee of the Quaid-i-Azam University (IRB-QAU-116). A volume of $3 \mathrm{~mL}$ of blood was collected from a healthy donor by venipuncture and diluted (1:1) with PBS. It was layered over $2 \mathrm{~mL}$ Histopaque-1077 and centrifuged at $800 \times \mathrm{g}$ for $20 \mathrm{~min}$. The buffy coat was aspirated into $5 \mathrm{~mL}$ of PBS and centrifuged at $350 \mathrm{rpm}$ for 4 min to pellet the lymphocytes. The pellet was suspended in $1 \mathrm{~mL}$ of RPMI-1640 and cell density was adjusted to get $1 \times 10^{5} \mathrm{cells} / \mathrm{ml}$. For cytotoxicity determination, $20 \mu \mathrm{l}$ of samples $(20 \mu \mathrm{g} / \mathrm{ml})$ or vincristine or $1 \%$ DMSO in PBS and $180 \mu \mathrm{l}$ of lymphocyte suspension were incubated in 96-well plate at $37{ }^{\circ} \mathrm{C}$ for $24 \mathrm{~h}$ in humidified $5 \%$ carbondioxide incubator (Panasonic, Japan MCO-18 AC-PE). Phytohaemagglutinin (PHA) was added in medium to stimulate lymphocyte growth. Afterwards, MTT assay was performed as described above.

\section{Protein kinase inhibition assay}

The protein kinase inhibition assay was performed by observing hyphae formation in purified isolates of Streptomyces $85 \mathrm{E}$ strain [21]. Microbial lawn was formed by spreading spores and mycelia fragments $(100 \mu \mathrm{l})$ of refreshed culture of Streptomyces on plates containing minimal ISP4 medium under sterile conditions. An aliquot of $5 \mu \mathrm{l}$ of each extract $(20 \mathrm{mg} / \mathrm{ml}$ of DMSO) was loaded onto sterile $6 \mathrm{~mm}$ filter paper discs. The impregnated sterile discs each having $100 \mu \mathrm{g} / \mathrm{disc}$ of extract were placed on the surface of the plates seeded with Streptomyces 85E. Surfactin (5 $\mu \mathrm{l} \mathrm{of} 4 \mathrm{mg} / \mathrm{ml}$ of DMSO) and DMSO impregnated discs served as positive and negative controls respectively. The plates were incubated for $72-96 \mathrm{~h}$ at $30{ }^{\circ} \mathrm{C}$ (time required for hyphae formation in Streptomyces 85E). Results were noted for the presence of bald or clear zone of inhibition around samples and control discs.

\section{Antileishmanial assay}

The in vitro antileishmanial evaluation of test extracts was carried out by employing MTT colorimetric assay as described previously [22]. A 6-7 days incubated culture of Leishmania tropica kwh 23 promastigotes was used. Concisely, parasites were grown in Medium 199 supplemented with $10 \%$ foetal bovine serum (FBS), $100 \mu \mathrm{g} / \mathrm{ml}$ streptomycin sulphate and $100 \mathrm{IU} / \mathrm{ml}$ penicillin $\mathrm{G}$ at $24{ }^{\circ} \mathrm{C}$. An aliquot of $180 \mu \mathrm{l}$ of promastigote culture at a preadjusted seeding density of $1 \times 10^{6}$ promastigotes $/ \mathrm{ml}$ was transferred to each well of 96 well plate having $20 \mu$ of test samples (containing $\leq 1 \%$ DMSO in PBS) at concentration of $100 \mu \mathrm{g} / \mathrm{ml}$. Amphotericin B $(0.33-0.004 \mu \mathrm{g} / \mathrm{ml})$ and $1 \%$ DMSO in PBS instead of test sample were employed as positive and negative controls respectively. The culture plate was then incubated at $24{ }^{\circ} \mathrm{C}$ for $72 \mathrm{~h}$ after which $20 \mu \mathrm{l}$ of pre-filter sterilized MTT solution $(4 \mathrm{mg} / \mathrm{ml}$ in distilled
$\mathrm{H}_{2} \mathrm{O}$ ) was added and plates were again incubated at $24{ }^{\circ} \mathrm{C}$ for $4 \mathrm{~h}$. After incubation supernatant was removed carefully without disturbing coloured formazan sediments. To dissolve the formazan sediments, $100 \mu \mathrm{l}$ of DMSO was added in each well, the plate was kept aside for $1 \mathrm{~h}$ to ensure full dissolution and the absorbance was measured at $540 \mathrm{~nm}$ using microplate reader. Samples showing more than 50\% cell mortality at $100 \mu \mathrm{g} / \mathrm{ml}$ were further analysed at lower concentrations i.e. $33.3,11.1,3.7$ and $1.23 \mu \mathrm{g} / \mathrm{ml}$. $\mathrm{IC}_{50}$ was calculated by using table curve $2 \mathrm{D}$ v5.01 software.

\section{a-Amylase inhibition assay}

Antidiabetic potential of test extracts was determined by $\alpha$-amylase inhibition assay following the standard protocol with minor modification [23]. The reaction mixture containing $15 \mu \mathrm{l}$ phosphate buffer ( $\mathrm{pH}$ 6.8), $25 \mu \mathrm{l} \alpha-$ amylase enzyme $(0.14 \mathrm{U} / \mathrm{ml}), 10 \mu \mathrm{l}$ sample $(4 \mathrm{mg} / \mathrm{ml}$ DMSO) and $40 \mu \mathrm{l}$ starch solution $(2 \mathrm{mg} / \mathrm{ml}$ in potassium phosphate buffer) was incubated at $50{ }^{\circ} \mathrm{C}$ for $30 \mathrm{~min}$ in 96 well plate followed by addition of $20 \mu \mathrm{l}$ of $1 \mathrm{M} \mathrm{HCl}$ to stop the reaction. Afterwards $90 \mu \mathrm{l}$ of iodine reagent (5 $\mathrm{mM}$ iodine, $5 \mathrm{mM}$ potassium iodide) was added to each well. Negative control was prepared without plant extracts whereas blank was prepared without extracts and amylase enzyme; each being replaced by equal quantities of buffer. Acarbose $(250 \mu \mathrm{M})$ was used as positive control. Absorbance of reaction plate after incubation was measured at $540 \mathrm{~nm}$. Activity was expressed as percent $\alpha$-amylase inhibition/mg dry extract and calculated by the following equation:

$$
\% \alpha \text {-amylase inhibition }=(\mathrm{Os}-\mathrm{On}) /(\mathrm{Ob}-\mathrm{On}) \times 100
$$

where $O n=$ Absorbance of negative control, $O s=$ Absorbance of sample and $O b=$ Absorbance of blank well.

\section{Antifungal assay}

The antifungal activity of test extracts was evaluated by agar disc diffusion method performed in triplicate [24]. The spores of test fungal strains [Aspergillus fumigatus (FCBP- 66), Mucor species (FCBP-0300), Aspergillus niger (FCBP-0198) and Aspergillus flavus (FCBP-0064)] were harvested in $0.02 \% \mathrm{v} / \mathrm{v}$ Tween 20 solution in $\mathrm{H}_{2} \mathrm{O}$ and their turbidity was adjusted according to McFarland 0.5 turbidity standard. Then $100 \mu \mathrm{l}$ of each harvested fungal strain was swabbed on plates containing Sabouraud Dextrose agar. Sterile filter paper discs impregnated with $5 \mu \mathrm{l}$ of test extracts $(20 \mathrm{mg} / \mathrm{ml}$ of DMSO), positive control (Clotrimazole, $4 \mathrm{mg} / \mathrm{ml}$ of DMSO) and negative control (DMSO) were placed on seeded plates and incubated for $24-48 \mathrm{~h}$ at $28{ }^{\circ} \mathrm{C}$. Afterwards, the average diameter $(\mathrm{mm})$ of growth inhibition zone around the 
samples as well as control treated discs was measured and recorded.

\section{Statistical analysis}

Data were expressed as mean \pm SD. The results obtained for phytochemical and cytotoxic assays were analysed statistically by one-way analysis of variance (ANOVA using the statistical package PASW Statistics 18).

\section{Results and discussion}

\section{Effect of extraction solvent on the extract yields}

The percentage recovery of extracts prepared by employing a total of 14 mono and binary solvent systems of escalating polarity has been summarized in Fig. 1 . Maximum amount of extract was recovered when DA was used as the extraction solvent with an extract yield of $10.52 \% \mathrm{w} / \mathrm{w}$ followed by D $(6.97 \% \mathrm{w} / \mathrm{w})$ and A $(6.75 \%$ $w / \mathrm{w})$ extracts respectively. On the other hand, it was least $(0.9 \% \mathrm{w} / \mathrm{w})$ in case of $\mathrm{NH}$ extract. An extraction procedure with superlative efficiency with respect to time/yield ratio is fundamental to accurately quantify the

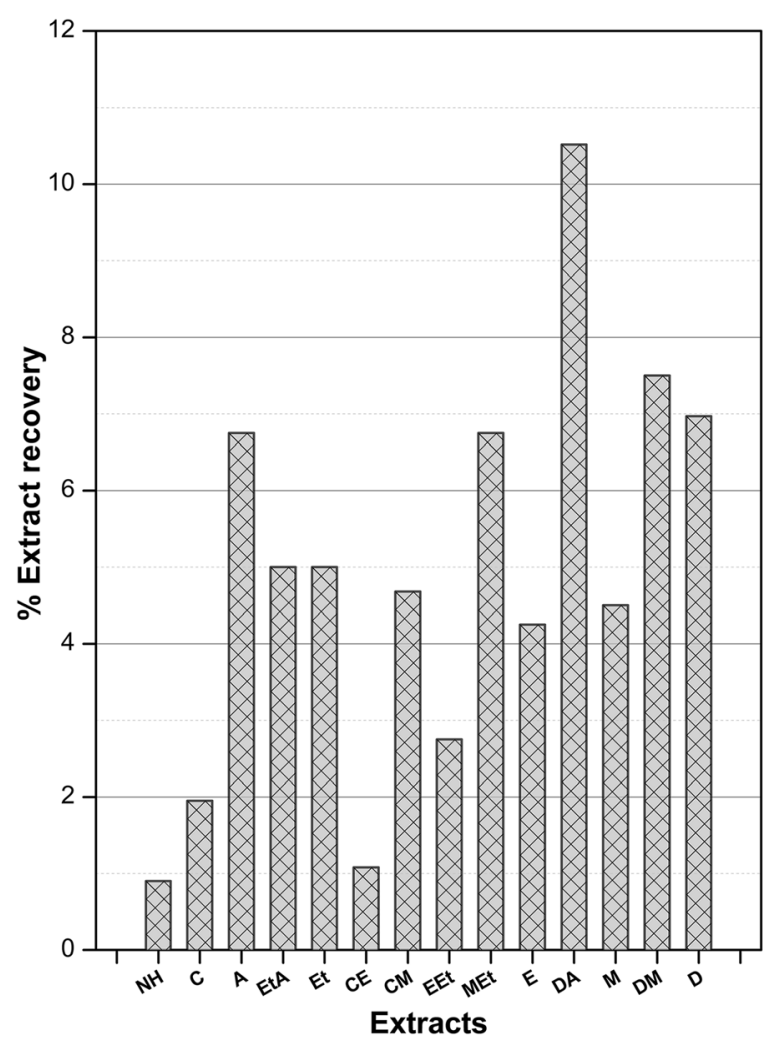

Fig. 1 Percent extract recovery of $Q$. dilatata using mono and binary (1:1) solvents for extraction. Values are presented as mean \pm standard error from triplicate investigation. $\mathrm{NH}$ : $\mathrm{n}$-hexane, $\mathrm{C}$ : Chloroform, $\mathrm{A}$ : Acetone, EtA: Ethyl acetate + Acetone, Et: Ethyl acetate, CE: Ethanol + Chloroform, CM: Chloroform + Methanol, EEt: Ethanol + Ethyl acetate, MEt: Methanol + Ethyl acetate, E: Ethanol, DA: Distilled water + Acetone, M: Methanol, DM: Distilled water + Methanol, D: Distilled water phytoconstituents [25]. This in turn also affects the biological evaluation of extracts. We observed a decreasing trend in extract yield along with decreasing polarity of extraction solvent. Thus, the use of sonication aided maceration with wide ranging solvent polarities in our study is a critical parameter in extraction yield optimization and its correlation with biological activities. This observation is in agreement with the previous report where effects of different extraction solvents, used in two extraction methods, on the total polyphenol contents of $Q$. coccifera fruits were studied and it was found that solvents with different polarities had significant effects on antioxidant activity [26]. The differences in the extract yields can be attributed to variable solubility of phytoconstituents based on their varied chemical composition in the plant [22].

\section{Phytochemical analysis}

In vitro phytochemical and antioxidant assays were performed by drawing a dose-response (calibration) curve of the reference compounds at multiple doses. The calculation of the sample was made in triplicate by using the equation drawn from the above curve.

\section{TPC}

The total gallic acid equivalent phenols in Q. dilatata extracts ranged from $21.37 \pm 0.21$ to $0.12 \pm 0.01 \mu \mathrm{g} \mathrm{GAE} / \mathrm{mg}$ DW with the highest content quantified in the DA extract. The phenolic content decreased in accordance with the following order; $\mathrm{DA}>\mathrm{D}>\mathrm{DM}>\mathrm{MEt}>\mathrm{A}>\mathrm{EtA}>\mathrm{M}>$ $\mathrm{Et}=\mathrm{E}>\mathrm{CM}>\mathrm{EEt}>\mathrm{C}>\mathrm{CE}>\mathrm{NH}$ (Fig. 3). Since, the polarities of polyphenols range from polar to non-polar, thus a wide range of solvents is required for their extraction. It has been observed that polar binary solvent systems are more efficient than mono solvent systems in the extraction of polyphenolic compounds which is in agreement with the results of previous study [27]. Thus polarity plays a key role in increasing solubility of phenols. A significant relationship between antioxidant capacity, reducing power and total phenolic content was found in this exploration, indicating that phenolic compounds are the major contributors to the antioxidant properties of this plant (Fig. 2). High levels of polyphenols are also reported in other species of Quercus such as Q. robur, Q. coccifera $[26,28]$. The HPLC-MS data of phenolic fraction of cork from Q. suber identified 15 phenolic components, with ellagic acid, followed by gallic and protocatechuic acids as the most abundant compounds [29]. The plant phenolics possess diverse biological activities such as anthelmintic [30], antifungal [31], antibacterial [32], antitumor [33], antiviral [34], antioxidant [35] and hepatoprotective [36]. The antioxidant properties have an important role in combating oxidative stress, cytotoxicity and cell death by scavenging free radicals or chelating trace elements thereby 

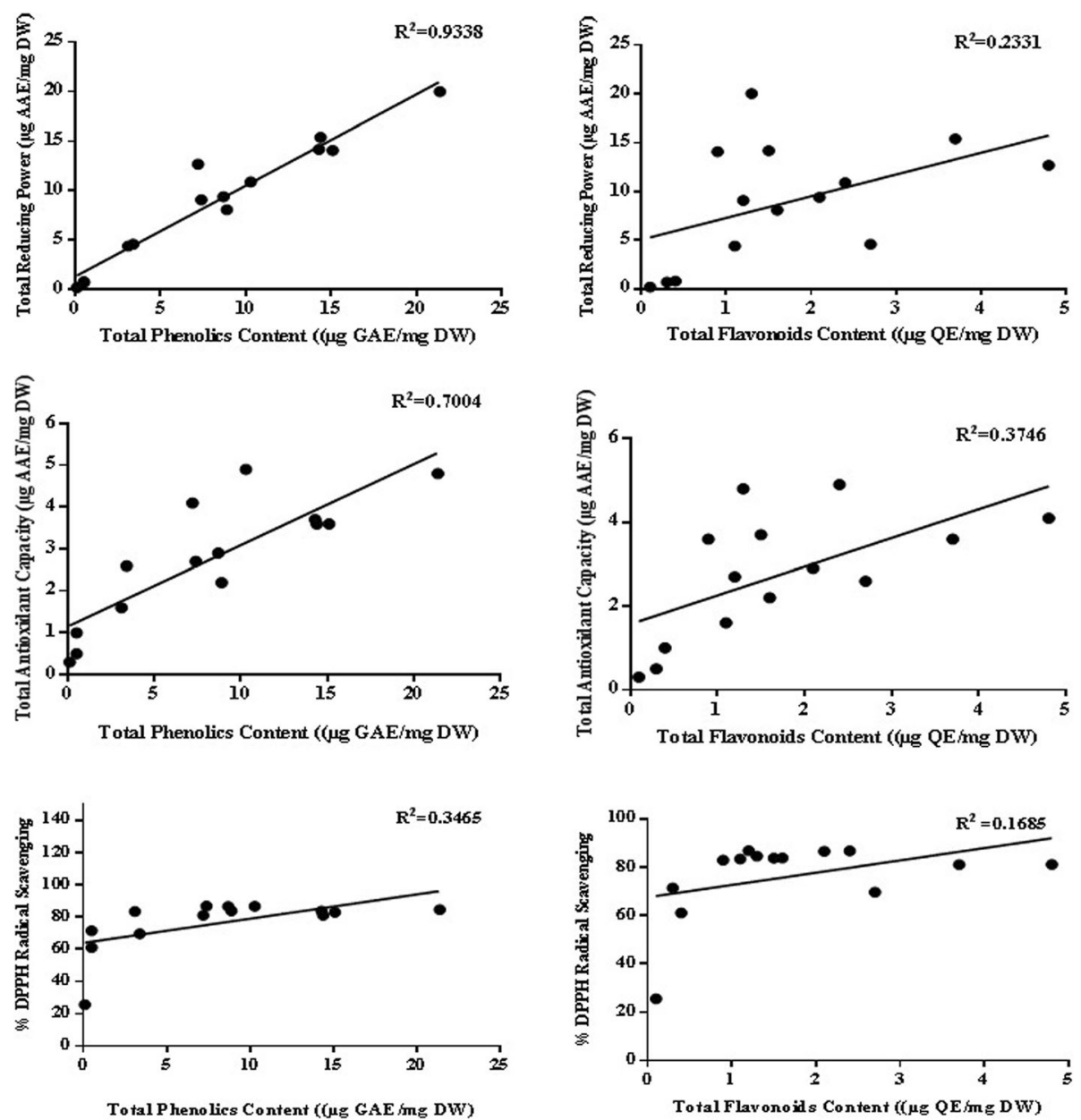

Fig. 2 Correlation of total phenolic and flavonoid content with antioxidant potential determining assays

strengthening the antioxidant defences [35]. Therefore, the presence of significant amounts of phenolic content in $Q$. dilatata proposes it a natural hub of the aforementioned pharmacological attributes.

\section{TFC}

The total flavonoid content of Q. dilatata aerial parts in terms of $\mu \mathrm{g} Q E / \mathrm{mg} D W$ are presented in Fig. 3. Among all the extracts, highest flavonoid content of $4.78 \pm 0.51 \mu \mathrm{g}$ $\mathrm{QE} / \mathrm{mg} \mathrm{DW}$ was recorded in aqueous extract followed by MEt extract $(3.76 \pm 0.16 \mu \mathrm{g} \mathrm{QE} / \mathrm{mg} \mathrm{DW})$. Lowest content was observed when $\mathrm{NH}$ was used alone with the value of $0.09 \pm 0.01 \mu \mathrm{g} \mathrm{QE} / \mathrm{mg} \mathrm{DW}$. The flavonoid content decreased with polarity in the following order; $\mathrm{D}>\mathrm{MEt}>\mathrm{Et}$ $>\mathrm{EtA}>\mathrm{E}>\mathrm{M}>\mathrm{A}>\mathrm{DA}>\mathrm{EEt}>\mathrm{CM}>\mathrm{DM}>\mathrm{C}>\mathrm{CE}>$ $\mathrm{NH}$. The genus Quercus is reported to be rich in flavonoid polyphenols as Brossa et al. [37] established that major constituents in Q. ilex leaves are flavanols and flavonols while Q. petraea and Q. robur are also found to be rich in flavonoids [38]. The compounds such as flavonoids, which hold hydroxyls groups, are responsible for the free radical scavenging activity in the plants and act through scavenging or chelating process [39]. Thus, the current flavonoid determination in polar extracts of $Q$. dilatata suggests it to be a valuable natural antioxidant.

\section{RP-HPLC}

Quantitative analysis of polyphenols as well as chromatographic fingerprinting of bioactive samples was done by RP-HPLC profiling (using 18 standards), after comparing their chromatographs with those of standards (Fig. 4). Quantitative determination of 11 detected polyphenols has been presented in Table 1 . Maximum contents of gallic acid, chlorogenic acid and p-coumaric acid were expressed in DA extract (5.282, 15.336 and $1.026 \mu \mathrm{g} / \mathrm{mg}$ extract respectively), while highest contents of pyrocatechol, catechin, coumarin and quercetin were observed in MEt extract $(0.361,2.291,0.368$ and $0.969 \mu \mathrm{g} / \mathrm{mg}$ extract respectively). In addition, maximum contents of vanillic acid, ferulic acid, rutin and kaempferol were observed in Et extract $(1.271,0.701,1.181$ and $0.291 \mu \mathrm{g} / \mathrm{mg}$ extract, 


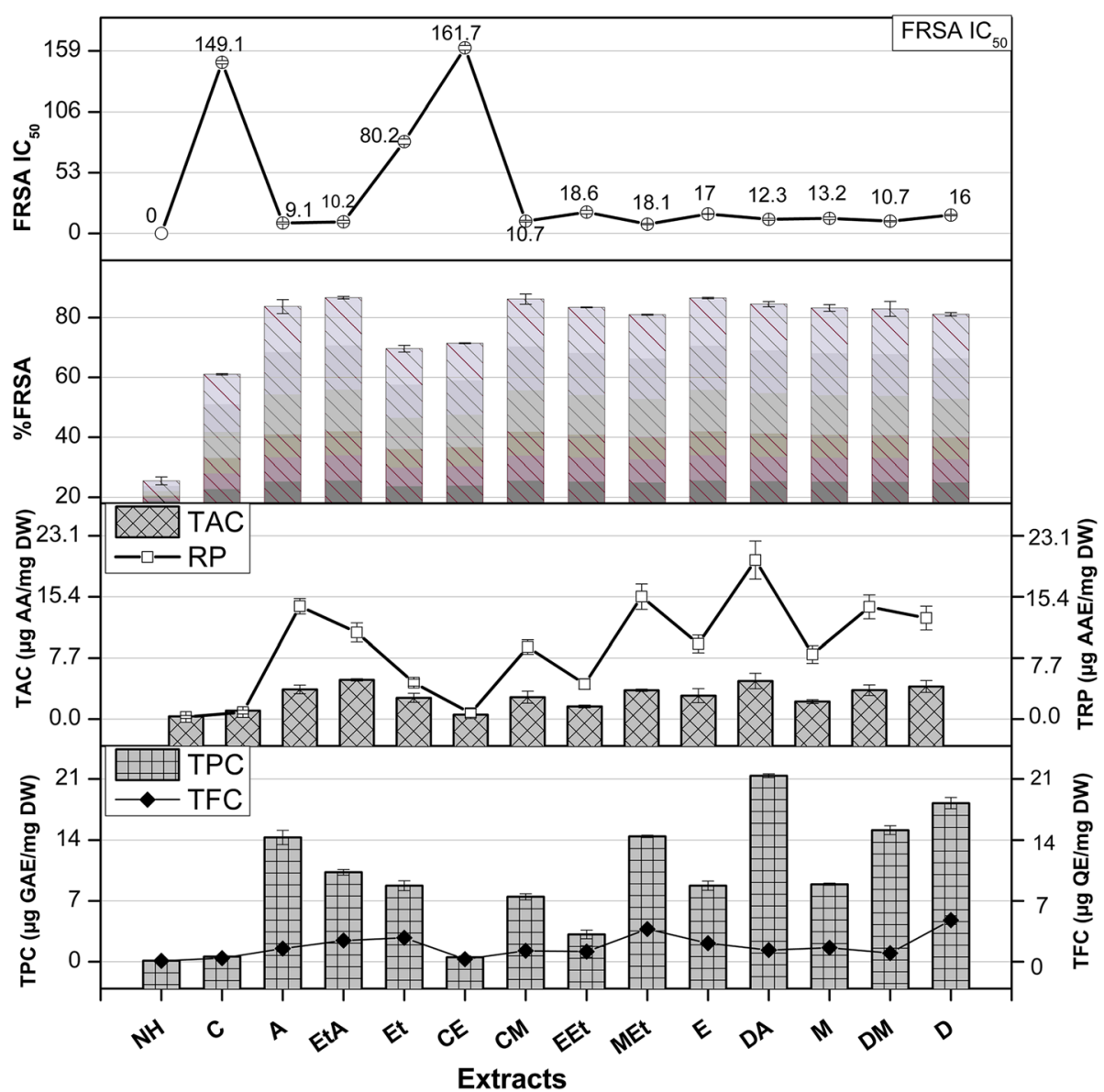

Fig. 3 TPC (Total phenolic content $\mu \mathrm{g}$ GAE/mg DW), TFC (Total flavonoid content $\mu \mathrm{g}$ QE/mg DW), TAC (Total antioxidant capacity $\mu \mathrm{g}$ AAE/mg DW), TRP (Total reducing power $\mu \mathrm{g} \mathrm{AAE/mg} \mathrm{DW)} \mathrm{and} \mathrm{\% FRSA} \mathrm{(radical} \mathrm{scavenging} \mathrm{activity)} \mathrm{of} Q$. dilatata in different solvents. Values are presented as mean \pm Standard deviation from triplicate investigation

respectively). Various solvents systems have been employed for the isolation of polyphenols. Their extraction efficiency is mainly effected by the choice of solvents and method of extraction [40]. Our results clearly indicate an increase in levels of detected polyphenols with ascending polarity of extraction solvents. Highest amounts of phenolic compounds were detected in DA mixture, which is supported by previous report in which aqueous acetone mixture $(70 \%)$ was found to be most effective for isolation of maximum amounts of condensed tannins from peas [41]. In terms of bioactivities, it is evident from the results that highest antioxidant potential shown by DA and MEt extracts might be attributed to the presence of hydroxycinnamic acids (chlorogenic acid, coumarin, p-coumarin), hydroxybenzoic acids (gallic acid) as well as flavonols (quercetin) and flavan-3- ols (catechin). Previous reports also support this hypothesis in which phenolics have been considered as strong candidates with potential antioxidant activity $[42,43]$. In addition to their antioxidant properties, these phenolic compounds have also shown chemopreventive and cytotoxic effects both in in vitro and in vivo models. Anthocyanins, kaempferol, quercetin, esters of coumaric acid and ellagic acid were found to be inhibitors of human oral (KB, CAL-27), breast (MCF-7), colon (HT-29, HCT-116), and prostate (LNCaP, DU-145) tumor cell lines in a dose-dependent manner [44]. Similarly, polyphenol constituents such as epigallocatechin-gallate (EGCG) and theaflavin have been demonstrated as potent anticancer agents in various animal models [45]. These studies suggest the possible role of polyphenols for the induction of cytotoxic potential of $Q$. dilatata extracts in the present study. Chromatograms of standards as well as phenols detected in the samples have been presented in Fig. 4 .

\section{Biological evaluation \\ Antioxidant assays}

FRSA The percent free radical scavenging activity (\% FRSA) of test samples, evaluated by measuring the discoloration of DPPH solution is shown in Fig. 3. The assay protocol relies on the conversion of stable purple coloured DPPH radical to its yellow-coloured diphenyl 


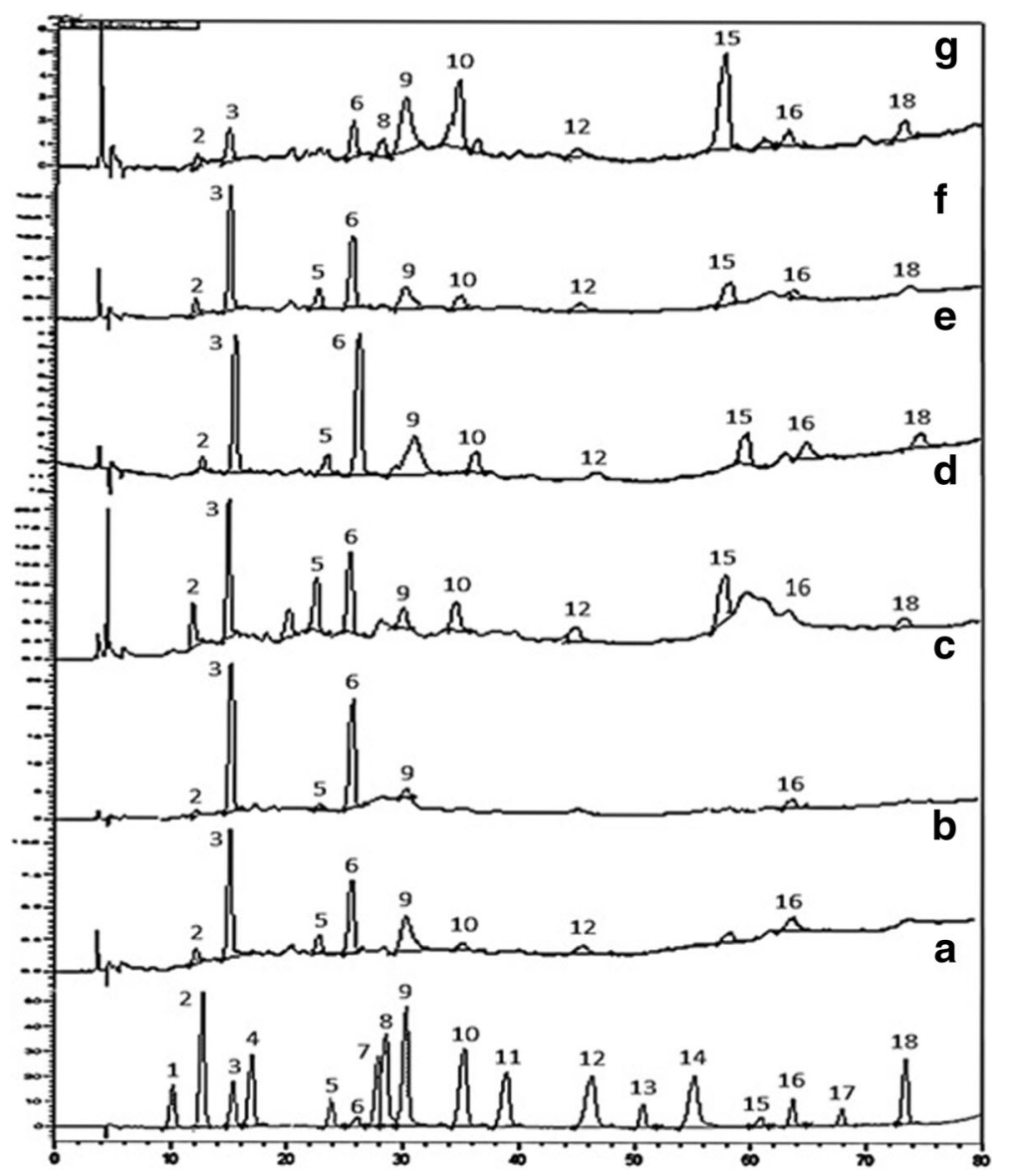

Fig. 4 RP-HPLC chromatograms of standard compounds (a) and DA (b), D (c), MEt (d), CM (e), M (f) and Et (g) extracts of Quercus dilatata showing phenolic compounds Hydroquinone (1), Pyrocatechol (2), Gallic acid (3), Resorcinol (4), Catechin (5), Chlorogenic acid (6), Caffeic acid (7), Vanillic acid (8), p-Coumaric acid (9), Ferulic acid (10), Sinapic acid (11), Coumarin (12), Salicylic acid (13), Trans cinnamic acid (14), Rutin (15), Quercetin (16), Ellagic acid (17) and Kaempferol (18). Values represented by bold letters are maximum phenolic contents detected in test samples

picryl hydrazine molecule by accepting electron or hydrogen radical from the donor antioxidant. The DPPH molecule is regarded as a stable free radical owing to the presence of a delocalized spare electron over the entire molecule that gives a characteristic absorption band at $517 \mathrm{~nm}$ [46]. Highest free radical scavenging efficiency was exhibited by MEt extract $\left(\mathrm{IC}_{50}=8.1 \pm 0.5 \mu \mathrm{g} / \mathrm{ml}\right)$ followed by A extract $\left(\mathrm{IC}_{50}=9.1 \pm 0.89 \mu \mathrm{g} / \mathrm{ml}\right)$. The scavenging effect of plant extracts on the DPPH radical decreased in the following order: $\mathrm{MEt}>\mathrm{A}>\mathrm{EtA}>\mathrm{CM}$ $>\mathrm{DM}>\mathrm{DA}>\mathrm{M}>\mathrm{D}>\mathrm{E}>\mathrm{EEt}>\mathrm{Et}>\mathrm{C}>\mathrm{CE}>\mathrm{NH}$. The radical scavenging efficiency of MEt, A, EtA, CM, $\mathrm{DM}$ and DA extracts is comparable, but the high extraction yields obtained by DA extract opens good perspectives for the exploitation of this extract in nutraceutical applications. The current scavenging results also support the previous findings where the polar ethyl acetate fraction of $Q$. dilatata exhibited the highest antiradical potential $\left(\mathrm{IC}_{50}=38.02 \mu \mathrm{g} / \mathrm{ml}\right)$ while the least quenching effect was manifested by the non-polar n-hexane fraction
[3]. Previously, the FRSA of Q. subar and Q. coccifera extracts, evaluated using this assay was found to be considerably higher than BHT and comparable to that of BHA (3-t-butyl-4-hydroxyanisole), quercetin and ascorbic acid $[29,47]$.

TAC The total antioxidant capacity (TAC) of various solvent soluble extracts of Q. dilatata is summarized in Fig. 3. The assay is based on antioxidant mediated reduction of Mo (VI) to Mo (V) resulting in the formation of green coloured phosphate/Mo (V) complex [22]. The total antioxidant capacity of the extracts was found to decrease in order of DA extract $(4.81 \pm 0.98 \mu \mathrm{g} \mathrm{AAE} / \mathrm{mg} \mathrm{DW})>\mathrm{D}>\mathrm{EtA}$ $>\mathrm{A}>\mathrm{DM}>\mathrm{MEt}>\mathrm{E}>\mathrm{CM}>\mathrm{Et}>\mathrm{M}>\mathrm{EEt}>\mathrm{C}>\mathrm{CE}>\mathrm{NH}$ extract with the value of $0.34 \pm 0.10 \mu \mathrm{g} A \mathrm{AE} / \mathrm{mg} \mathrm{DW}$. The presence of a significant correlation between TAC and TPC $\left(R^{2}=0.7004\right)$ and a non-significant correlation between TAC and TFC $\left(R^{2}=0.3746\right)$ suggests that phenols other than flavonoids are the major contributors towards the antioxidant activity of Q. dilatata crude extracts (Fig. 2). 
Table 1 Phenolic composition ( $\mu \mathrm{g} / \mathrm{mg}$ extract) of six different Quercus dilatata extracts

\begin{tabular}{|c|c|c|c|c|c|c|c|}
\hline \multirow[t]{2}{*}{ Standards } & \multirow{2}{*}{$\begin{array}{l}\text { Retention } \\
\text { time } \\
\text { (min) }\end{array}$} & \multicolumn{6}{|c|}{ Samples } \\
\hline & & Et & CM & MEt & DA & M & $\mathrm{D}$ \\
\hline Hydroquinone & 10.07 & - & - & - & - & - & - \\
\hline Pyrocatechol & 12.06 & 0.049 & 0.013 & 0.361 & 0.232 & 0.111 & 0.017 \\
\hline Gallic acid & 15.24 & 0.534 & 0.499 & 2.822 & 5.282 & 2.112 & 1.382 \\
\hline Resorcinol & 17.48 & - & - & - & - & - & - \\
\hline Catechin & 23.61 & - & 0.150 & 2.291 & 1.380 & 0.808 & 0.095 \\
\hline Chlorogenic acid & 25.80 & 1.009 & 2.699 & 9.478 & 15.336 & 7.122 & 5.162 \\
\hline Caffeic acid & 27.51 & - & - & - & - & - & - \\
\hline Vanillic acid & 28.21 & 1.271 & - & - & - & - & - \\
\hline p-Coumaric acid & 30.16 & 0.534 & 0.146 & 0.232 & 1.026 & 0.339 & 0.036 \\
\hline Ferulic acid & 34.87 & 0.701 & 0.046 & 0.461 & 0.173 & 0.192 & - \\
\hline Sinapinic acid & 38.48 & - & - & - & - & - & - \\
\hline Coumarin & 44.85 & 0.105 & 0.105 & 0.368 & - & 0.149 & - \\
\hline Salicylic acid & 50.05 & - & - & - & - & - & - \\
\hline Trans cinnamic acid & 54.44 & - & - & - & - & - & - \\
\hline Rutin & 58.79 & 1.181 & 0.094 & - & 0.245 & 0.407 & - \\
\hline Quercetin & 63.13 & 0.164 & 0.060 & 0.969 & 0.616 & 0.085 & 0.059 \\
\hline Ellagic acid & 67.35 & - & - & - & - & - & - \\
\hline Kaempferol & 73.06 & 0.291 & 0.069 & 0.284 & - & 0.129 & - \\
\hline
\end{tabular}

- Not detected

Previously the total antioxidant activity of methanol extract was reported as $64 \mathrm{mg}$ equivalent of $\mathrm{BHT} / \mathrm{g}$ of Q. infectoria nutgalls which is quite high in comparison to the antioxidant capacity of the methanolic extract of $Q$. dilatata aerial parts $(2.20 \pm 0.25 \mu \mathrm{g} \mathrm{AAE} / \mathrm{mg} \mathrm{DW})$ as determined in the current analysis [39]. However, overall yield of aerial parts per plant is also much higher than the nutgalls. This still buttress the potential of this plant as a source of natural antioxidants.

TRP Figure 3 shows the reductive power of various solvent extracts of $Q$. dilatata. It was observed that the maximum extraction efficiency in terms of highest reducing power was achieved in the DA extract $(20.03 \pm 2.4 \mu \mathrm{g}$ $\mathrm{AAE} / \mathrm{mg} \mathrm{DW})$. The total reducing capacity of test extracts was found to decrease in order of DA $>\mathrm{MEt}>$ $\mathrm{A}>\mathrm{DM}>\mathrm{D}>\mathrm{EtA}>\mathrm{E}>\mathrm{CM}>\mathrm{M}>\mathrm{Et}>\mathrm{EEt}>\mathrm{C}>\mathrm{CE}>\mathrm{NH}$. A significant relationship between TRP and TPC $\left(\mathrm{R}^{2}=0.9338\right)$ while a non-significant correlation between TRP and TFC $\left(R^{2}=0.2331\right)$ is observed in this study (Fig. 2 ). Therefore, it is suggested that phenolic compounds might be the major contributors to the reducing properties of this plant. The various antioxidant potential assays of medicinal plants used in diet therapy during postpartum healthcare in Rajasthan, India revealed that among all the plants tested, the Q. infectoria extract possessed highest FRSA and reducing potential of $90.20 \%$ of DPPH inhibition and $1115 \mathrm{mM} \mathrm{Fe} / \mathrm{g}$ respectively [48]. The reducing properties are generally associated with the presence of reductones which have been allied to the antioxidant action through breakage of the free radical chain by donating a hydrogen atom. Consequently, a direct correlation have been observed between the antioxidant capacity and reducing power of certain plant extracts which is in agreement with the results of our study [49].

\section{Cytotoxicity assessment}

Brine shrimp lethality assay

Cytotoxicity prospective of the plant was tested against brine shrimp larvae to establish its bioactivity profile. The degree of lethality was found to be directly proportional to the concentration of test extracts when analyzed by using serial dilution method. Out of 14 organic extracts screened for cytotoxic activity, $21.42 \%$ of the extracts demonstrated $\mathrm{LC}_{50}$ value below $50 \mu \mathrm{g} / \mathrm{ml}$ and were categorized as highly cytotoxic while $57.14 \%$ of them were considered as moderately cytotoxic ( $\mathrm{LC}_{50}$ value $\geq 50$ but $\leq 200 \mu \mathrm{g} / \mathrm{ml}$ ). The remaining $21.42 \%$ of the extracts had $\mathrm{LC}_{50}$ values $>200 \mu \mathrm{g} / \mathrm{ml}$ and were considered to have a weak cytotoxic activity under the experimental conditions. The results from screening of $Q$. dilatata extracts against $A$. salina larvae are shown in Table 2. The positive control, doxorubicin demonstrated an $\mathrm{LC}_{50} 5.93 \mu \mathrm{g} / \mathrm{ml}$. Among all the individual extracts 


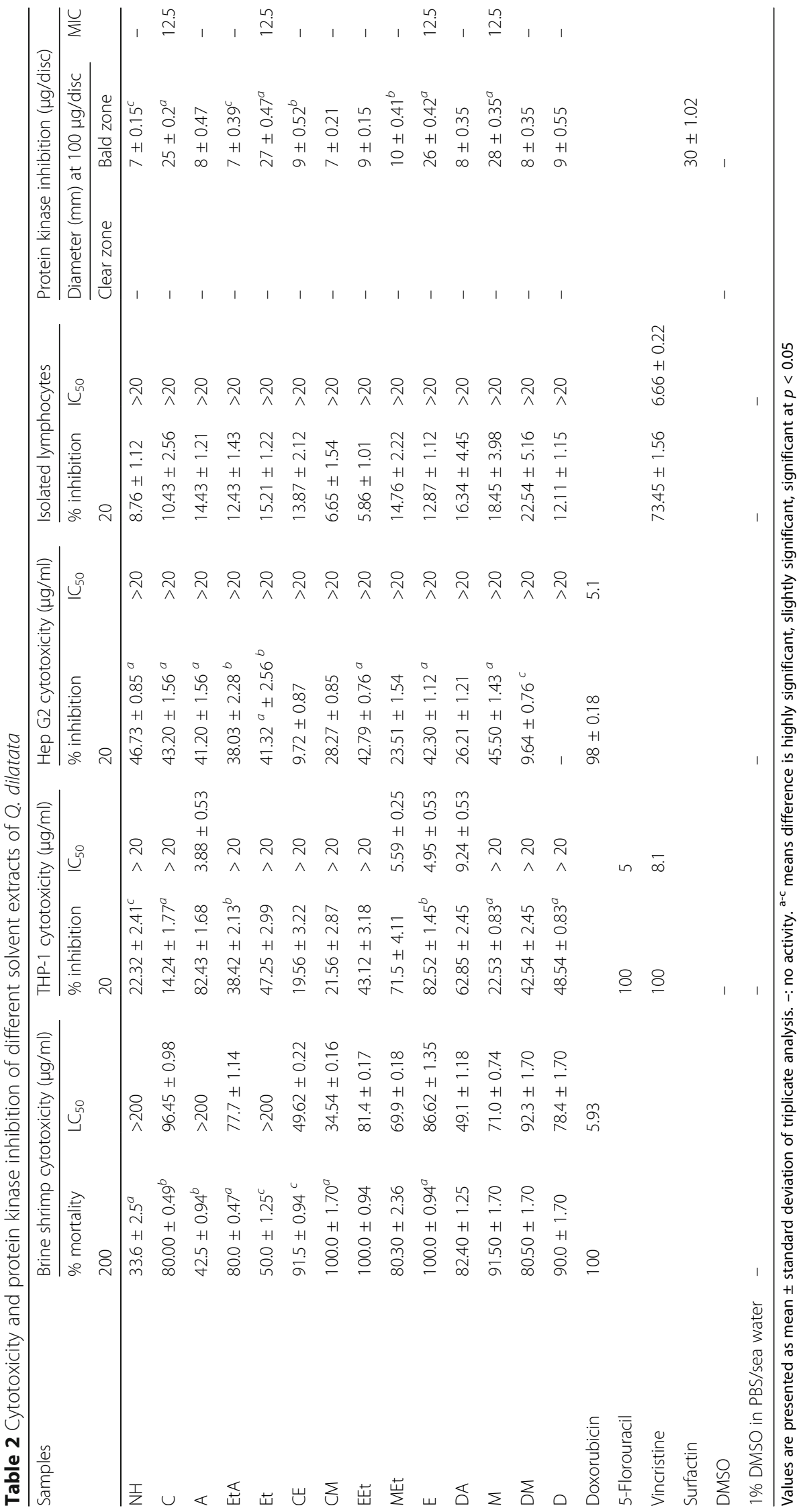


CM extract was found to be the most cytotoxic exhibiting the $\mathrm{LC}_{50} 34.54 \pm 0.16 \mu \mathrm{g} / \mathrm{ml}$ signifying the effectiveness of a moderately polar binary solvent system against a highly polar or non-polar solvent system. A working concentration of $<1 \%$ in DMSO was employed to prepare test mixtures as it is a safer solvent in brine shrimp lethality test compared to others such as Tween 20 [50]. Brine shrimp lethality assay is a simple and high throughput cytotoxicity test of bioactive chemicals. It is based on the killing ability of test compounds of a simple zoological organism, the brine shrimps. Artemia nauplii are used extensively in research and toxicology due to the commercial availability of dried cysts from which live test material can be hatched at will. This assay draws extrapolations on the safety of the plant extracts and further illustrates trends of their biological activities. In bioactivity evaluation of the plant extracts by brine shrimp bioassay, an $\mathrm{LC}_{50}$ value of less than $1000 \mu \mathrm{g} / \mathrm{ml}$ is considered to be cytotoxic [51]. In our study, $100 \%$ of the screened extracts revealed $\mathrm{LC}_{50}$ values $<1000 \mu \mathrm{g} / \mathrm{ml}$ suggesting the presence of cytotoxic bioactive compounds responsible for the observed deaths.

\section{Cytotoxicity against THP-1 cell line}

Advances in prevention and treatment of cancer requires continuous development of novel and improved chemotherapeutic and chemopreventive agents. The plant based anticancer drug discovery such as vincristine, vinblastine, etoposide, paclitaxel, camptothecin, topotecan and irinotecan accentuate the need for their further exploration as fundamental [52]. Keeping in view the prodigious cytotoxic potential illustrated by brine shrimp lethality assay; the plant extracts were further screened for an in vitro cytotoxic activity using human leukemia (THP-1 ATCC\# TIB-202) cell line (Table 2). Samples were found to be more cytotoxic at higher concentrations as compared to lower concentrations. Among all the test extracts, most prominent inhibition was shown by A extract exhibiting $82.43 \pm 1.68 \%$ inhibition at $20 \mu \mathrm{g} / \mathrm{ml}$ concentration and an $\mathrm{IC}_{50} 3.88 \pm 0.53 \mu \mathrm{g} / \mathrm{ml}$ which is comparable to the standard drugs 5 -florouracil and vincristine with $\mathrm{IC}_{50} 5 \mu \mathrm{g} / \mathrm{ml}$ and $8.1 \mu \mathrm{g} / \mathrm{ml}$ respectively. Previously methanol extract of $Q$. dilatata aerial parts demonstrated a noteworthy antitumor activity exhibiting $84.78 \%$ tumour inhibition at a concentration of $1000 \mu \mathrm{g} / \mathrm{ml}$ in potato disc antitumor assay [53]. Previously water infusions of mature and fresh Q. resinosa leaves were evaluated for antioxidant activity and genotoxic effects on HeLa cells. Results showed that fresh leaves infusions increase the oxidative process and other damage to DNA and may serve as a potential source of phenolics with anticancer activity [54]. In the present analysis, there was no significant correlation observed between TPC and THP-
1 cell line cytotoxicity $\left(R^{2}=0.0542\right)$ or TFC and THP-1 cell cytotoxicity $\left(\mathrm{R}^{2}=0.3288\right)$.

\section{Cytotoxicity against Hep G2 cell line}

The cytotoxicity of $Q$. dilatata crude extracts against Hep G2 human hepatoma cell line was determined as percent inhibition at $20 \mu \mathrm{g} / \mathrm{ml}$ concentration in comparison to the anticancer drug doxorubicin (Table 2). A moderate antiproliferative activity was exhibited by $50 \%$ of the test extracts with $\mathrm{IC}_{50} 46.73 \pm 0.85-$ $38.03 \pm 2.28 \%$. The highest inhibition was exhibited by the non-polar $\mathrm{NH}$ extract $(46.73 \pm 0.85 \%)$ followed by $\mathrm{M}>\mathrm{C}>\mathrm{EEt}>\mathrm{E}>\mathrm{Et}>\mathrm{EtA}>\mathrm{CM}>\mathrm{DA}>\mathrm{MEt}>$ $\mathrm{DM}>\mathrm{A}=\mathrm{D}$. Hepatoma is amongst the two major forms of primary liver cancers and is the most common widespread cancer in the world which is preceded by the occurrence of hepatocellular damage via ROS and the generation of chronic inflammation [55]. Therefore, the antioxidant stature and cytotoxicity of $Q$. dilatata extracts as revealed in the present exploration suggests it to be a worthy hit for the identification of lead compounds against hepatoma. In the present analysis, there was no significant correlation observed between TPC and Hep G2 cell cytotoxicity $\left(\mathrm{R}^{2}=0.128\right)$ or TFC and Hep G2 cell cytotoxicity $\left(R^{2}=0.0542\right)$.

\section{Cytotoxicity against isolated lymphocytes}

Cytotoxicity of sample extracts was also tested against isolated lymphocytes at the same concentration employed for cytotoxicity assessment against THP-1 and Hep G2 cell lines i.e. $20 \mu \mathrm{g} / \mathrm{ml}$ to compare effect at same concentration (Table 2). The results showed that none of the extracts was cytotoxic against the isolated lymphocytes indicating selective response against cancer cell lines which is beneficial in targeting cancer cells while limiting damage to normal cells. Vincristine, the positive control employed in the assay exhibited significant cytotoxicity against normal lymphocytes with $\mathrm{IC}_{50} 6.66 \pm 0.22 \mu \mathrm{g} / \mathrm{ml}$. The selective inhibition of THP-1 and Hep G2 cells indicate prospective of Q. dilatata as candidate for anticancer drug development.

\section{Protein kinase inhibition assay}

The results of zones of protein kinase inhibition recorded for the test samples are presented in Table 2. A direct relationship was observed between concentrations and activity. Among all the extracts, a noteworthy inhibition zone of $28 \quad \pm \quad 0.35 \mathrm{~mm}$ bald phenotype $(\mathrm{MIC}=12.5 \mu \mathrm{g} / \mathrm{ml})$ was formed around $\mathrm{M}$ extract loaded disc followed by Et $(27 \pm 0.47 \mathrm{~mm}$ bald $)$ and $\mathrm{E}$ extracts (26 $\pm 0.42 \mathrm{~mm}$ bald). These results are comparable with $30 \mathrm{~mm}$ bald zone of surfactin. The non-toxic effect of DMSO (negative control) was confirmed by the absence of growth inhibition zone. In recent years, there has been a tremendous surge for the discovery of protein kinase 
enzyme inhibitors especially from plants. Protein phosphorylation at serine/threonine and tyrosine residues by protein kinases is one of the major mechanisms regulating biological processes including apoptosis, cell proliferation, cell differentiation, and metabolism. Deregulated phosphorylation at serine/threonine and tyrosine residues by protein kinases resulting from genetic alterations acquired early in tumorigenesis are often the cause of cancer. In this respect, inhibition of protein kinases has emerged as a promising target for cancer treatment [21]. Protein kinase activity is critical for the aerial hyphae formation of Streptomyces and this prerequisite was exploited in the present study as kinase inhibitory effect of extracts represents their possible anticancer potential.

\section{Antileishmanial potential}

Antileishmanial capability of different extracts of $Q$. dilatata has been evaluated for the first time in the current study. From the screening performed, EtA and A extracts exhibited remarkable and comparable leishmanicidic potential with $\mathrm{IC}_{50} 12.91 \pm 0.02 \mu \mathrm{g} / \mathrm{ml}$ and $14.40 \pm 0.01$ respectively and it was found to be absent in the polar extracts (Fig. 5). Amphotericin B, the positive control exhibited $\mathrm{IC}_{50} 0.01 \mu \mathrm{g} / \mathrm{ml}$. Although the antipromastigote activity of both the extracts is comparable but the percentage yield of A extract is more than EtA extract suggesting it as the most efficient solvent system for the reclamation of leishmanicidic potential of Q. dilatata in terms of yield and bioactivity. Leishmaniasis that represents a significant disease burden especially in the developing countries requires exploration of new less toxic chemotherapeutic agents due to variable effectiveness of the current treatments, their associated side effects and absence of any vaccine [56]. Previously

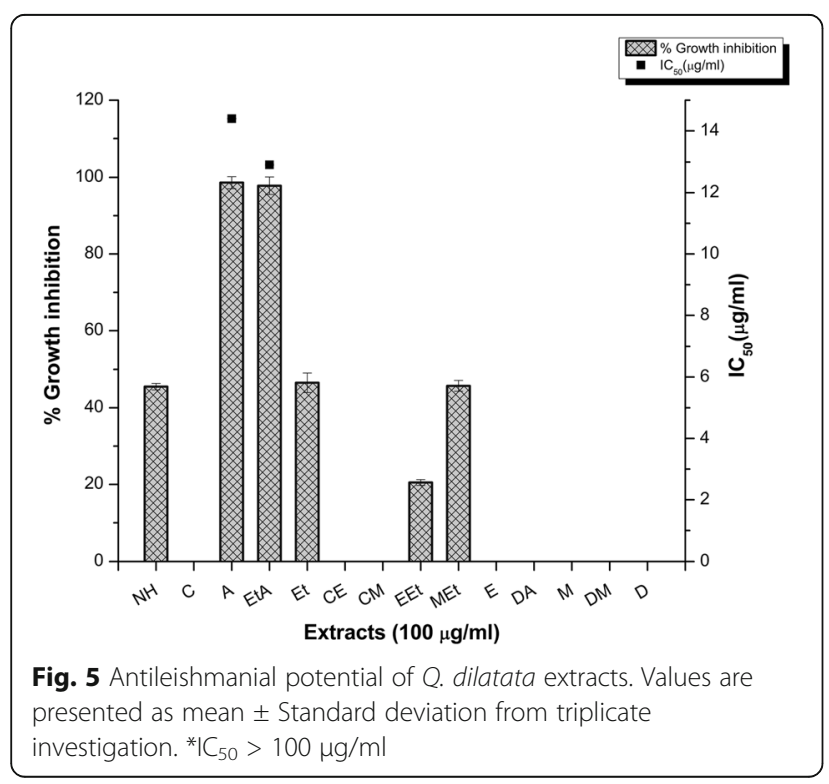

this was confined to northern sphere of Pakistan but now it is widely spreading throughout the country with cutaneous and visceral leishmaniasis being the major threats [57]. The World Health Organization advocates the use of traditional medicine for the treatment of tropical diseases such as leishmaniasis due to their established safe use in humans [58]. Previously, $Q$. insignis ethanol bark extract showed promising activity against $L$. amazonensis promastigotes with low cytotoxic activity and it was suggested as a worthy candidate for further phytochemical exploration [2].

In the present study the $C$ extract showed profound kinase inhibitory activity, cytotoxicity against shrimps and antileishmanial activity but did not exhibit any significant anti-proliferative potential against THP-1 or Hep G2 cell lines. The observed lethality against shrimps and promastigotes might be due to the inhibition of various kinases mandatory for cell survival. On the other hand among all the analyzed samples, E extract displayed significant cytotoxicity against shrimps and THP-1 leukemia cell line as well as protein kinase inhibition; therefore, mechanistic studies are required to extrapolate these activities for its possible anticancer role. In the present analysis, there was no significant correlation observed between TPC and antipromastigote activity $\left(R^{2}=0.0077\right)$ or TFC and antileishmanial potential $\left(R^{2}=0.0165\right)$.

\section{a-Amylase inhibition assay}

All the fourteen extracts of varying polarities prepared from $Q$. dilatata were subjected to standard chromogenic $\alpha$-amylase inhibition assay and the results are presented in Fig. 6. In our present study, C, EEt, CM and Et extracts were found to have some acarbose like antidiabetic activity

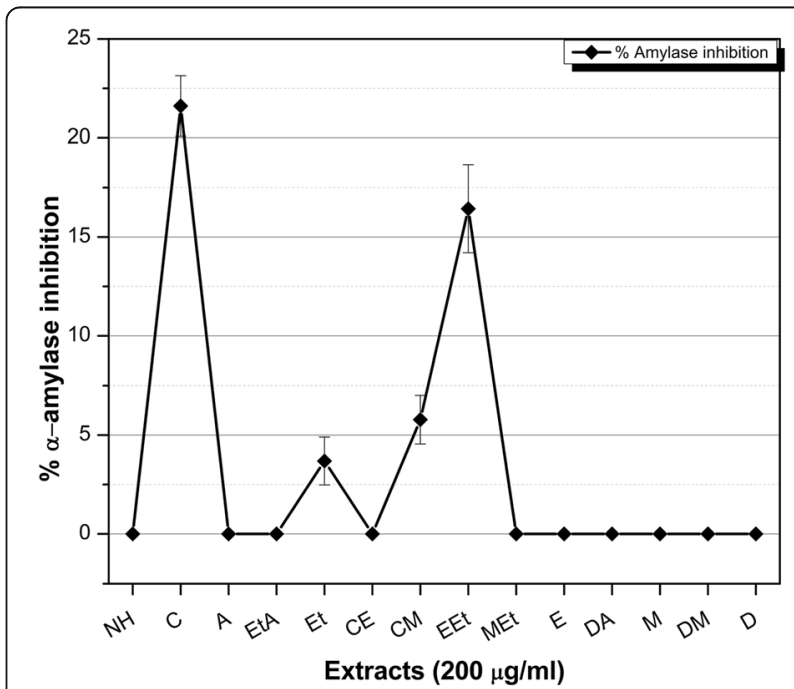

Fig. 6 a-amylase inhibition by $Q$. dilatata extracts. The $I_{50}$ of acarbose (positive control) $=33.73 \pm 0.12 \mu \mathrm{g} / \mathrm{ml}$. Experiment was performed in triplicate and values are presented as mean \pm standard deviation 
i.e. $21.61 \pm 1.53,16.43 \pm 2.23,5.78 \pm 1.23$ and $3.69 \pm 1.21 \%$ respectively. $\mathrm{IC}_{50}$ values were not calculated due to comparatively moderate inhibition $(<50 \%)$ of subject enzyme. Acarbose, the positive control inhibited $80.34 \pm 1.12 \%$ of $\alpha$-amylase enzyme's activity and demonstrated an $\mathrm{IC}_{50} 33.73 \pm 0.12 \mu \mathrm{g} / \mathrm{ml}$. The hallmark in diabetes control is the management of blood glucose level which may be achieved through the use of oral hypoglycaemic agents, insulin secretagogues, and carbohydrate hydrolysing enzyme inhibitors. Plants continue to play an important role in the treatment of diabetes, particularly in developing countries where most of the people have limited resources and do not have access to modern treatment. Even in the developed countries there is a shift to the use of alternative approaches to treat diabetes, such as plant-based medicines owing to the side effects associated with the use of insulin and oral hypoglycaemic agents [59]. Therefore, it is crucial to identify and explore the inhibitors of carbohydrate hydrolysing enzymes such as $\alpha$-amylase from natural sources having fewer side effects. Inhibitors of $\alpha$-amylase reduce the glucose peaks that can occur after a meal, slowing the speed with which amylase can convert starch to simple sugars until the body can deal with it. This is of particular importance in people with diabetes, where low insulin levels prevent extracellular glucose from being cleared quickly from the blood. Previous studies on $\alpha$ amylase inhibitors isolated from medicinal plants suggest that several potential inhibitors of this enzyme belong to flavonoid class of phytochemicals [60]. However in the present analysis there was no significant correlation observed between TPC and amylase inhibition $\left(R^{2}=0.258\right)$ or TFC and enzyme inhibition $\left(\mathrm{R}^{2}=0.258\right)$.

\section{Antifungal assay}

The plant's antifungal potential was assessed against four strains of filamentous fungi, the results of which are summarized in Table 3. The data indicate that a moderate antifungal activity was exhibited by almost all the extracts against the tested strains. In case of $A$. fumigatus the growth inhibition zones ranged between 7 and $8 \mathrm{~mm}$ for all the extracts. A maximum inhibition zone was displayed by the $\mathrm{M}, \mathrm{D}$ and $\mathrm{E}$ extracts against $F$. solani $(9 \pm 1.54 \mathrm{~mm})$, A. niger $(9 \pm 0.75 \mathrm{~mm})$ and $A$. flavus $(9 \pm 0.98 \mathrm{~mm})$ respectively. The absence of growth inhibition zone around negative control disc confirmed the non-toxic effect of DMSO whereas standard drug Clotrimazole exhibited maximum activity at a concentration of $10 \mu \mathrm{g} /$ disc. It was observed that extraction solvent polarity did not profoundly affect antifungal proficiency of various Q. dilatata extracts. Since, well known plant secondary metabolites exhibiting antifungal activity include flavonoids, phenols and phenolic
Table 3 Antifungal activity of Q. dilatata extracts tested against filamentous fungi

\begin{tabular}{lllll}
\hline Samples & \multicolumn{3}{l}{ a Diameter of growth inhibition zone at $100 \mu \mathrm{g} /$ disc } \\
\cline { 2 - 5 } & A. fumigatus & F. Solani & A. niger & A. flavus \\
\hline $\mathrm{NH}$ & $7 \pm 0.24$ & $8 \pm 1.85$ & $7 \pm 1.21$ & $7.5 \pm 0.45$ \\
$\mathrm{C}$ & $7.5 \pm 1.0$ & $7 \pm 0.25$ & $7.5 \pm 1.2$ & $7.5 \pm 0.25$ \\
$\mathrm{~A}$ & $7.5 \pm 0.56$ & $7.5 \pm 1.21$ & $7.5 \pm 1.5$ & $7.5 \pm 0.32$ \\
EtA & $7 \pm 0.45$ & $8 \pm 0.56$ & $7.5 \pm 0.78$ & $6.5 \pm 0.41$ \\
Et & $8 \pm 0.52$ & $8 \pm 1.40$ & $7 \pm 0.25$ & $8 \pm 0.35$ \\
CE & $7.5 \pm 0.45$ & $7 \pm 0.35$ & $8 \pm 0.50$ & $7.5 \pm 0.30$ \\
CM & $7 \pm 0.35$ & $8 \pm 0.40$ & $7 \pm 0.57$ & $7 \pm 0.25$ \\
EEt & $7.5 \pm 1.2$ & $7 \pm 0.35$ & $7.5 \pm 0.20$ & $7 \pm 0.65$ \\
MEt & $8 \pm 0.40$ & $7 \pm 0.65$ & $8 \pm 1.10$ & $7.5 \pm 0.67$ \\
E & $8 \pm 0.45$ & $7.5 \pm 1.43$ & $8 \pm 1.0$ & $9 \pm 0.98$ \\
DA & $7 \pm 0.40$ & $7 \pm 1.50$ & $7 \pm 1.67$ & $8 \pm 0.55$ \\
M & $7 \pm 0.50$ & $9 \pm 1.54$ & $8 \pm 0.76$ & $7.5 \pm 0.69$ \\
DM & $7.5 \pm 0.5$ & $8 \pm 0.78$ & $7.5 \pm 0.80$ & $6.5 \pm 0.55$ \\
D & $8 \pm 0.55$ & $7.5 \pm 0.45$ & $9 \pm 0.75$ & $7 \pm 0.40$ \\
Clotrimazole & $23 \pm 0.12$ & $24 \pm 0.98$ & $22 \pm 1.03$ & $24 \pm 1.01$ \\
DMSO & - & - & - & - \\
\hline
\end{tabular}

${ }^{a}$ Zone of inhibition including the diameter of disc $(6 \mathrm{~mm})$. In each disc, the sample size was $100 \mu \mathrm{g}$ per disc $(5 \mu \mathrm{l})$ in disc diffusion assay. -: no activity. Values are presented as mean \pm standard error from triplicate investigation

glycosides, unsaturated lactones, sulphur compounds, saponins, cyanogenic glycosides and glucosinolates [61].

\section{Conclusion}

The quantification of important polyphenols and determination of antimicrobial activity in various crude extracts of Q. dilatata is helpful in explaining some of its traditional uses. The use of a wide-ranging solvent system polarity proved crucial to demonstrate phytochemical and biological profiling of the subject plant. The current study proposes DA extract of Q. dilatata as a potential source of phytochemicals with substantial antioxidant capability while its $\mathrm{M}$ extract has protective activity against various tumorigenic kinases. Similarly, $C$ extract was significantly cytotoxic against brine shrimps, THP-1 human leukemia cells and leishmanial promastigotes. In conclusion, the present study endorses use of polarity dependent extraction as an important factor for the determination of biological spectrum of $Q$. dilatata and prospects it as substantial source of bioactive metabolites.

\section{Abbreviations}

DMSO: Dimethyl sulfoxide; DPPH: 2, 2-diphenyl-1-picrylhydrazyl; FRSA: Free radical scavenging activity; $I C_{50}$ : 50\% inhibitory concentration; $L C_{50}$ : Lethal concentration causing 50\% mortality; MIC: Minimum inhibitory

concentration; ROS: Reactive oxygen species; TAC: Total antioxidant capacity; TFC: Total flavonoid contents; TPC: Total phenolic contents; TRP: Total reducing power; ZOI: Zone of inhibition 


\section{Acknowledgements}

The authors are thankful to Prof. Dr. Rizwana Aleem Qureshi, Department of Plant sciences, Faculty of Biological sciences, Quaid-i-Azam University Islamabad, Pakistan for identifying the plant sample.

\section{Funding}

We acknowledge the financial support given by Higher Education Commission Pakistan, under PhD indigenous fellowship program to finance this research project.

\section{Availability of data and materials}

All the data and materials have been provided in the main manuscript.

\section{Authors' contributions}

MA executed all experimental work and compiled the data. HF helped in manuscript write up and execution of experiments. MQ and BG were involved in HPLC analysis and interpretation of data. IU contributed in study design, supervised the execution of experiments and revised the manuscript. All authors have read and approved the final manuscript.

\section{Ethics approval and consent to participate}

Informed consent was taken from volunteers and protocol was followed according to international ethical guidelines after approval from the ethical committee of the Quaid-i-Azam University (IRB-QAU-116).

\section{Consent for publication}

Not applicable.

\section{Competing interests}

The authors declare that they have no competing interests.

\section{Publisher's Note}

Springer Nature remains neutral with regard to jurisdictional claims in published maps and institutional affiliations.

\section{Author details}

'Department of Pharmacy, Faculty of Biological Sciences, Quaid-i-Azam University, Islamabad 45320, Pakistan. ${ }^{2}$ Institute of Sustainable Halophyte Utilization, University of Karachi, Karachi 75270, Pakistan.

\section{Received: 15 November 2016 Accepted: 27 July 2017}

\section{Published online: 03 August 2017}

\section{References}

1. Ashraf A, Sarfraz RA, Rashid MA, Shahid M. Antioxidant, antimicrobial, antitumor, and cytotoxic activities of an important medicinal plant (Euphorbia royleana) from Pakistan. J Food Drug Anal. 2015;23(1):109-15

2. Monzote L, Piñón A, Setzer W. Antileishmanial potential of tropical rainforest plant extracts. Medicines. 2014;1 (1):32.

3. Ihtisham M, Ihsan-ul-Haq, Sarwar S, Mirza B. HPLC-DAD analysis and free radical scavenging potential of Quercus Dilatata L. Pak J Bot. 2013:45(S1):577-81.

4. Sarwat SZ, Ahmad N. Screening of potential medicinal plants from district sawat specific for controlling women diseases. Pak J Bot. 2012;44(4):1193-8.

5. Dar M. Ethno botanical uses of Plants of Lawat District Muzaffarabad, Azad Jammu and Kashmir. Asian J Plant Sci. 2003;2(9):680-2.

6. Khan MA, Khan MA, Hussain M, Mujtaba G. Medicinal plants used in folk recipes by the inhabitants of himalayan region Poonch Valley Azad Kashmir (Pakistan). J Basic Appl Sci. 2012:8:35-45.

7. Qasim M, Aziz I, Rasheed M, Gul B, Khan MA. Effect of extraction solvents on polyphenols and antioxidant activity of medicinal halophytes. Pak J Bot. 2016;48(2):621-7.

8. Haq IU, Ullah N, Bibi G, Kanwal S, Ahmad MS, Mirza B. Antioxidant and cytotoxic activities and phytochemical analysis of Euphorbia wallichii root extract and its fractions. Iran J Pharm Res. 2012;11(1):241-9.

9. Bray HG. Kinetic studies of the metabolism of foreign organic compounds. 3. The conjugation of phenols with glucuronic acid. Biochem J. 1952:3(52):416.

10. Jafri L, Saleem S, Haq IU, Ullah N, Mirza B: In vitro assessment of antioxidant potential and determination of polyphenolic compounds of Hedera nepalensis K. Koch. Arab J Chem. 2014;10;3699-3702.
11. Harborne JB. General procedures and measurement of total phenolics. Methods Plant Biochem. 1989:1:1-28.

12. Proestos C, Boziaris IS, Nychas GJE, Komaitis M. Analysis of flavonoids and phenolic acids in Greek aromatic plants: Investigation of their antioxidant capacity and antimicrobial activity. Food Chem. 2006;95(4):664-71.

13. Qasim M, Abideen Z, Adnan M, Gulzar S, Gul B, Rasheed M, Khan M Antioxidant properties, phenolic composition, bioactive compounds and nutritive value of medicinal halophytes commonly used as herbal teas. S Afr J Bot. 2016;110:240-250.

14. Araruna MKA, Santos KKA, da Costa JGM, Coutinho HDM, Boligon AA, Stefanello ST, Athayde ML, Saraiva RA, da Rocha JBT, Kerntopf MR, et al. Phenolic composition and in vitro activity of the Brazilian fruit tree Caryocar coriaceum Wittm. Eur J Integr Med. 2013:5(2):178-83.

15. Hogg JS, Lohmann DH, Russell KE. The kinetics of reaction of 2, 2-diphenyl1-picrylhydrazyl with phenols. Can J Chem. 1961:39:1588-94.

16. Krishnaveni M. Antioxidant activity of selected plants. Plant Physiol. 1968:43:193-200

17. Lea $\mathrm{CH}$. A note on the Chapman and McFarlane method for the estimation of reducing groups in milk powder. Analyst. 1947;72(857):336-40.

18. Haq IU, Ullah N, Bibi G, Kanwal S, Ahmad MS, Mirza B. Antioxidant and cytotoxic activities and phytochemical analysis of Euphorbia wallichii root extract and its fractions. Iran J Pharm Res (2012). 2010;11(1):241-9.

19. Vichai V, Kirtikara K. Sulphorhodaminen B colorimetric assay for cytotoxicity screening. Nat Protoc. 2006;1(3):1112-6.

20. Waseem D, Butt AF, Haq I-u, Bhatti MH, Khan GM. Carboxylate derivatives of tributyltin (IV) complexes as anticancer and antileishmanial agents. DARU Pharm Sci. 2017;25(8).

21. Yao G, Sebisubi FM, Voo LYC, Ho CC, Tan GT, Chang LC. Citrinin Derivatives from the Soil Filamentous Fungus Penicillium sp. H9318. J Braz Chem Soc. 2011;22(6):1125-9.

22. Khan K, Fatima H, Taqi MM, Zia M, ur-Rehman T, Mirza B, Haq I-u. Phytochemical and in vitro biological evaluation of Artemisia scoparia Waldst. \&amp; Kit for enhanced extraction of commercially significant bioactive compounds. J Appl Res Med Aromat Plants. 2015;2(3):77-86.

23. Kim J-S, Kwon C-S, Son KH. Inhibition of alpha-glucosidase and amylase by luteolin, a flavonoid. Biosci Biotechnol Biochem. 2000;64(11):2458-61.

24. Sharma A, Chandraker S, Patel VK, Ramteke P. Antibacterial Activity of Medicinal Plants Against Pathogens causing Complicated Urinary Tract Infections. Indian J Pharm Sci. 2009;71(2):136-9.

25. Celeghini RMS, Vilegas JHY, Lanças FM. Extraction and Quantitative HPLC Analysis of Coumarin in Hydroalcoholic Extracts of Mikania glomerata Spreng: ("guaco") Leaves. J Braz Chem Soc. 2001;12:706-9.

26. Hayouni EA, Abedrabba M, Bouix M, Hamdi M. The effects of solvents and extraction method on the phenolic contents and biological activities in vitro of Tunisian Quercus coccifera L. and Juniperus phoenicea L. fruit extracts. Food Chem. 2007;105(3):1126-34.

27. Dent M, Dragovi'-Uzelac V, Peni M, Brn M, Bosiljkov T, Levaj B. The effect of extraction solvents, temperature and time on the composition and mass fraction of polyphenols in dalmatian wild sage (Salvia officinalis L.) extracts. Food Technol Biotechnol. 2013;51(1):84-91.

28. Dudonné S, Vitrac $X$, Coutière $P$, Woillez M, Mérillon J-M. Comparative study of antioxidant properties and total phenolic content of 30 plant extracts of industrial interest using DPPH, ABTS, FRAP, SOD, and ORAC assays. J Agric Food Chem. 2009;57(5):1768-74.

29. Santos $S A O$, Pinto $P C R O$, Silvestre AJD, Neto CP. Chemical composition and antioxidant activity of phenolic extracts of cork from Quercus suber L. Ind Crop Prod. 2010;31(3):521-6.

30. Silva N, Fernandes Júnior A. Biological properties of medicinal plants: a review of their antimicrobial activity. J Venomous Anim Toxins Incl Trop Dis 2010:16:402-13.

31. Chena F, Longa X, Yua M, Liua Z, Liua L, Shao H. Phenolics and antifungal activities analysis in industrial crop Jerusalem artichoke (Helianthus tuberosus L.) leaves. Ind Crop Prod. 2013;47:339-45.

32. Kubo I, Fujita K, Nihei K, Nihei A. Antibacterial activity of akyl gallates against Bacillus subtilis. J Agric Food Chem. 2004;52(5):1072-6.

33. You BR, Moon HJ, Han YH, Park WH. Gallic acid inhibits the growth of HeLa cervical cancer cells via apoptosis and/or necrosis. Food Chem Toxicol. 2010:48(5):1334-40.

34. Uozaki M, Yamasaki H, Katsuyama Y, Higuchi M, Higuti T, Koyama AH. Antiviral effect of octyl gallate against DNA and RNA viruses. Antivir Res. 2007;73(2):85-91. 
35. Kumar S, Chashoo G, Saxena AK, Pandey AK. Parthenium hysterophorus: a probable source of anticancer, antioxidant and anti-HIV agents. Biomed Res Int. 2013;2013:11.

36. Ferk F, Chakraborty A, Jager W, Kundi M, Bichler J, Misik M, Wagner KH, Grasl-Kraupp B, Sagmeister S, Haidinger G, et al. Potent protection of gallic acid against DNA oxidation: results of human and animal experiments. Mutat Res. 2011;715(1-2):61-71.

37. Brossa R, Casals I, Pintó-Marijuan M, Fleck I. Leaf flavonoid content in Quercus ilex L. resprouts and its seasonal variation. Trees. 2009;23(2):401-8.

38. Popović BM, Štajner D, Ždero R, Orlović S, Gali Z. Antioxidant characterization of Oak extracts combining spectrophotometric assays and chemometrics. Sci World J. 2013;2013:8.

39. Asifa M, Ansaria SH, Haquea MR, Kalama N. Estimation of total phenolic, flavonoid contents and antioxidant activity in the nut galls of Quercus infectoria olivier. J Pharm Res. 2012:5(7):3855-7.

40. Goli AH, Barzegar M, Sahari MA. Antioxidant activity and total phenolic compounds of pistachio (Pistachia vera) hull extracts. Food Chem. 2005;92(3):521-5.

41. Chavan UD, Shahidi F, Naczk M. Extraction of condensed tannins from beach pea (Lathyrus maritimus L.) as affected by different solvents. Food Chem. 2001;75(4):509-12.

42. Balasundram N, Sundram K, Samman S. Phenolic compounds in plants and agri-industrial by-products: Antioxidant activity, occurrence, and potential uses. Food Chem. 2006;99(1):191-203.

43. Dai J, Mumper RJ. Plant phenolics: extraction, analysis and their antioxidant and anticancer properties. Molecules. 2010;15:7313-52.

44. Zhang $Y$, Seeram NP, Lee R, Feng L, Heber D. Isolation and identification of strawberry phenolics with antioxidant and human cancer cell antiproliferative properties. J Agric Food Chem. 2008;56(3):670-5.

45. Huang MT, Xie JG, Wang ZY, Ho CT, Lou YR, Wang CX, Hard GC, Conney AH. Effects of tea, decaffeinated tea, and caffeine on UVB light-induced complete carcinogenesis in SKH-1 mice: demonstration of caffeine as a biologically important constituent of tea. Cancer Res. 1997;57(13):2623-9.

46. Fatima H, Khan K, Zia M, Ur-Rehman T, Mirza B, Haq I-u. Extraction optimization of medicinally important metabolites from Datura innoxia Mill. an in vitro biological and phytochemical investigation. BMC Complement Altern Med. 2015;15(1):376.

47. Genç Y, Yüzbaşioğlu M, Harput ÜŞ, Kuruüzüm-uz A. Antioxidant activity and total phenolic content of Quercus coccifera L. FABAD J Pharm Sci. 2012;37:17-22.

48. Jain N, Goyal S, Ramawat K. Evaluation of antioxidant properties and total phenolic content of medicinal plants used in diet therapy during postpartum healthcare in Rajasthan. Int J Pharm Pharm Sci. 2011;3(3):248-53.

49. Abdel-Hameed E-SS. Total phenolic contents and free radical scavenging activity of certain Egyptian Ficus species leaf samples. Food Chem. 2009;114(4):1271-7.

50. Wu C. An important player in brine shrimp lethality bioassay: The solvent. J Adv Pharm Technol Res. 2014;5(1):57-8.

51. Nguta JM, Mbaria JM, Gakuya DW, Gathumbi PK, Kabasa JD, Kiama SG. Evaluation of acute toxicity of crude plant extracts from Kenyan biodiversity using brine shrimp, Artemia salina L. (Artemiidae). Open Conf Proc J. 2012;3:30-4.

52. Greenlee H. Natural products for cancer prevention. Semin Oncol Nurs. 2012;28(1):29-44.

53. Jamil M, Mirza B, Yasmeen A, Khan MA. Pharmacological activities of selected plant species and their phytochemical analysis. J Med Plants Res. 2012;6(37):5013-22.

54. Rocha-Guzmán NE, Gallegos-Infante JA, González-Laredo RF, ReynosoCamacho R, Ramos-Gómez M, Garcia-Gasca T, Rodríguez-Muñoz ME, Guzmán-Maldonado SH, Medina-Torres L, Lujan-García BA. Antioxidan activity and genotoxic effect on HeLa cells of phenolic compounds from infusions of Quercus resinosa leaves. Food Chem. 2009;115(4):1320-5.

55. Machana S, Weerapreeyakul N, Barusrux S. Anticancer effect of the extracts from Polyalthia evecta against human hepatoma cell line (HepG2). Asian Pac J Trop Biomed. 2012;2(5):368-74.

56. Sadeghi-Nejad B, Saki J, Khademvatan S, Nanaei S. In vitro antileishmanial activity of the medicinal plant - Satureja khuzestanica Jamzad. J Med Plant Res. 2011;5(24):5912-5.

57. Shah NA, Khan MR, Nadhman A. Antileishmanial, toxicity, and phytochemical evaluation of medicinal plants collected from Pakistan Biomed Res Int. 2014;2014:7.
58. Filho VC, Meyre-Silva C, Niero R, Bolda Mariano LN, Gomes do Nascimento F, Vicente Farias I, Gazoni VF, et al.: Evaluation of antileishmanial activity of selected Brazilian plants and identification of the active principles. Evid Based Complement Alternat Med 2013, 2013:7.

59. Patel DK, Kumar R, Laloo D, Hemalatha S. Diabetes mellitus: An overview on its pharmacological aspects and reported medicinal plants having antidiabetic activity. Asian Pac J Trop Biomed. 2012;2(5):411-20.

60. Kyriakis E, Stravodimos GA, Kantsadi AL, Chatzileontiadou DS, Skamnaki VT, Leonidas DD. Natural flavonoids as antidiabetic agents. The binding of gallic and ellagic acids to glycogen phosphorylase b. FEBS Lett. 2015:589(15):1787-94.

61. Quiroga EN, Sampietro AR, Vattuone MA. Screening antifungal activities of selected medicinal plants. J Ethnopharmacol. 2001;74(1):89-96.

\section{Submit your next manuscript to BioMed Central and we will help you at every step:}

- We accept pre-submission inquiries

- Our selector tool helps you to find the most relevant journal

- We provide round the clock customer support

- Convenient online submission

- Thorough peer review

- Inclusion in PubMed and all major indexing services

- Maximum visibility for your research

Submit your manuscript at www.biomedcentral.com/submit
Biomed Central 